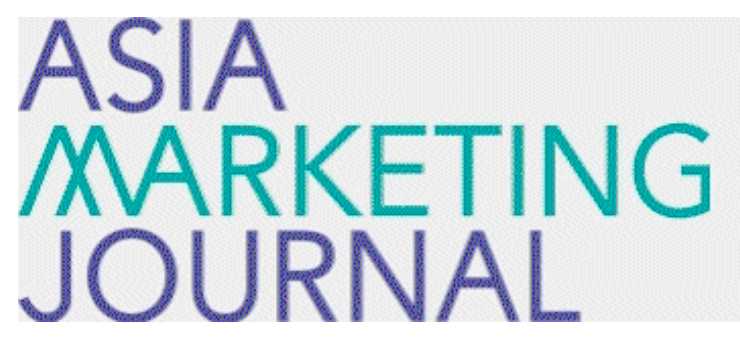

ASIA MARKETING JOURNAL

Volume 8 | Issue 2

Article 3

7-31-2006

\title{
인터넷 쇼핑에서 인터넷 자기효능감의 역할
}

Ho Bae Lee

Nam Kyeong Kwon

Follow this and additional works at: https://amj.kma.re.kr/journal

Part of the Marketing Commons

\section{Recommended Citation}

Lee, Ho Bae and Kwon, Nam Kyeong (2006) "인터넷 쇼핑 에서 인터넷 자기효늘감의 역할," Asia Marketing Journal: Vol. 8 : Iss. 2 , Article 3.

Available at: https://doi.org/10.53728/2765-6500.1167

This Article is brought to you for free and open access by Asia Marketing Journal. It has been accepted for inclusion in Asia Marketing Journal by an authorized editor of Asia Marketing Journal. 


\title{
인터넷 쇼핑에서 인터넷 자기효능감의 역할
}

\section{The Role of Internet Self-efficacy in Internet Shopping}

\author{
이 호 배(Lee, Hobae) ${ }^{*}$ \\ 권 남 경 (Kwon, Nam Kyeong)**
}

본 연구는 인터넷 쇼핑 시 소비자의 인터넷 자기효능감 정도가 특정 인터넷 쇼핑몰에서의 구매 의도에 미치는 영향을 알아보았다. 구체적으로 소비자의 인터넷 자기호능감이 특정 인터넷 쇼핑 웹사이트 태도에 미치는 영향을 알아보았고, 이과정에서 인터넷 자기효능감이 인터넷 이용이나 특 정 웹사이트를 지속적으로 방문하고 이용하게 하는 플로우(flow)와 인터넷 쇼핑에서 구매를 꺼리 게 하는 지각된 위험이 매개되어서 웹사이트에 대한 태도에 미치는 영향을 실증적으로 분석한 결 과는 아래와 같다.

첫째, 인터넷 자기효능감은 플로우(flow)에 긍정적 영향을 미칠 뿐만 아니라 지각된 위험을 낮 추는 긍정적 효과가 있는 것으로 나타났다. 이것은 인터넷 자기효능감이 높을수록 인터넷을 이용 하면서 자발적 흥미를 더 느끼게 되고, 인터넷 쇼핑 구매에 대한 우려와 걱정을 나타내는 지각된 위험이 낮아지는 것을 의미한다.

둘째, 플로우(flow)는 인터넷 쇼핑 사이트 태도에 긍정적 영향을 미치고, 지각된 위험은 인터넷 쇼핑 사이트 태도에 부정적 영향을 미치는 것으로 나타났다. 또한 인터넷 쇼핑 사이트에 대한 웹 사이트 태도는 구매의도에 긍정적 영항을 미치는 것으로 나타났다. 이것은 소비자가 인터넷 사용 을 통해서 자발적 흥미를 느낄수록 인터넷쇼푱 사이트에 대한 태도가 호의적인 반면 소비자가 인 터넷 쇼핑 사이트에 대해서 느끼는 위함이 클수록 그 사이트에 대한 태도는 비호의적임을 의미한 다. 또한 인터넷 사이트에 대한 태도가 호의적일수록 그 사이트에서 구매할 의도는 높아진다는 것 을 확인할 수 있다.

끝으로, 인터넷 사이트에 대한 지각된 위험이 클수록 플로우(flow)에 부정적 영향을 미친다는 것은 밝혀지지 않았다.

핵심개념: 자기 효능감, 인터넷 자기 효능감, 지각된 위험. 플로우(flow), 구매의도

* 홍익대학교 경영대학 교수(hblee@hongik.ac.kr)

** 홍익대학교 대학원 경영학 석사(soda123@hanmail.net) 


\section{I. 서 론}

인터넷 쇼핑이 급속도로 확대됨에 따라. 기존 전통적 마케팅을 설명하는데 이용되었던 개념들 이 인터넷 마케팅상황에 적용되는 연구들이 봇 물처럼 쏟아져 나오고 있다. 이미 소비자들은 특정 물건을 구매할 생각을 갖게 되면 우선적으 로 인터넷을 이용해서 다양한 제품정보수집 및 비교를 한 후 그 정보를 갖고 직접 매장에 가서 가격협상을 할 정도로 인터넷을 이용한 제품 정 보검색이 보편화되고 있기 때문이다. 이와 같이 소비자들이 인터넷을 통해서 관심있는 정보거리 들을 찾아다니면서 플로우를 즐기거나. 제품정 보에 대한 효율적 탐색을 수행할 수 있게 되었 고, 기업은 소비자의 다양한 욕구에 맞는 정보 를 실시간으로 제공하게 됨에 따라 공급자와 소 비자의 직접적인 정보교환 및 거래가 가능해졌 다. 더구나 최근의 구매환경은 과거처럼 구매현 장에서 판매원에제 문의하거나 전문가의 도움을 받아서 구매의사결정을 할 수 없기 때문에, 본 인이 직접 인터넷검색을 통해서 정보들 찾아내 서 비교한 후 구매결정을 할 수밖에 없다. 따라 서 개인의 인터넷검색능력에 따라서 구매 성과 가 달라질 수 있다. 더구나 소비자가 인터넷상 에서 구매를 하려고 할 때 개인정보 보안에 대 한 불안감을 느끼거나, 하루가 다르게 진화되는 인터넷기술을 수월하게 다룰 수 있는 자신감이 없다면, 기업의 입장에서도 일반 사람들이 인터 넷을 통해서 구매할 수 있도록 인터넷 환경을 보편화시키는데 장애요인이 될 수 있다.

이러한 상황에서 소비자들이 인터넷 이용에 대한 자신감은 인터넷 사용에 대한 지각된 위
험을 줄일 수 있고, 인터넷정보검색을 하면서 플로우를 즐길 수 있도록 해준다. 그동안 지각 된 위험(김종호, 신용섭 2000: 박유식, 한명희 2001: 전성률, 허종호, 강석준 2003; Bozionelos 1997)이나 플로우(김명소 1999; 이명수, 박종 희. 김도일 2001; 두정완 2003: Novak et al. 2000)가 구매의도에 미치는 영향을 알아보는 기존연구들은 많았지만, 지각된 위험이나 플로 우에 영향을 주는 요인에 대해서는 별로 연구 가 없었다.

따라서 본 연구에서는 자신의 인터넷 사용능 력에 대한 믿음 즉 인터넷자기효능감이 특정인 터넷 쇼핑몰 사이트에 대한 지각된 위험에 어 떻게 영향을 주는 가를 알아보려고 한다. 이와 함께 소비자들이 쇼핑을 하기 위한 실용적 목 적으로 인터넷을 검색하고 있지만 이때 느끼는 플로우 상태에 대해서도 인터넷 자기 효능감이 어떻게 영향을 미치는 지 알아 볼 필요가 있다. 결국 이러한 인터넷 자기효능감이 인터넷을 통 한 거래에서 수반되는 불확실성에 대한 소비자 의 지각과 인터넷의 지속적인 사용을 이끄는 자발적 흥미(playfulness)인 플로우에 미치는 영향과 태도 및 구매의도와의 관계에 대해 알 아보려고 한다.

\section{II. 이론적 배경}

\section{1 인터넷 자기효능감 (Internet Self-efficacy)}

자기효능감은 '행동변화를 중재하는 공통적인 
인지 메커니즘으로서 개인이 갖고 있는 기술을 의미하는 것이 아니라 개인이 소유하고 있는 기술을 어느 정도 행할 수 있는가에 대한 판단 이라고 정의되었고(Bandura 1977), 어떤 과업 이나 행동을 효과적으로 수행하기 위해서는 실 제 능력과 함께 자기효능감이 필요하다고 하였 다. 이는 자기효능감이 객관적인 능력에 대한 평가가 아니라 자신의 능력에 대한 스스로의 판단을 의미하는 지각된 자기호능감(perceived self-efficacy)이다(Bandura 1977).

자기효능감은 성과 성취, 대리 경험, 언어적 설득. 감정적 환기로부터 기인한다(Bandura 1977 , 1986). 또한 자기효능감은 중대성 (magnitude: 사람들이 그들이 달성할 수 있다고 믿는 직무 어려움의 수준), 강도(strength: 중대성에 대한 확신), 일반화(generality)의 3 가지 구성요소를 가지며. 새로운 정보와 경험이 습득되면서 또는 시간이 지남에 따라서 변하는 역동적인 개념이 다. Murphy(1988)에 의하면. 특정 시스템 사용 에 대해 자기효능감이 낮은 사람은 시스템 이 용 능력에 대한 자신감이 낮고, 어떤 정보가 제 시되었을 때 정보에 대해서 질문하기 보다는 그 정보를 그대로 받아들이는 경향이 강하다. 반대로, 자기효능감이 높은 사람은 시스템 사용 능력에 대한 자신감이 높고, 자신에 대한 학습 에 더 저항적이라고 하였다.

최근에는 자기효능감 개넘이 컴퓨터 및 인터 넷 사용에 대한 개인의 수용에 대한 연구로 확 대되어서 이것을 인터넷 효능감이라고 한다. 인 터넷 자기효능감은 인터넷 사용에 대한 자신의 능력에 대한 믿음으로서, 낮은 인터넷 자기효능 감이란 인터넷 사용 능력에 대해서 자신감이 부족하고, 자신의 인터넷 사용기술에 대해서 불
만족하거나 불편함을 느끼는 것을 의미한다. 따 라서 이들은 인터넷 사용과 적응 행동이 미숙 하다. 일반적으로 인터넷 초보 사용자는 인터넷 을 사용하는데 불편을 느끼고, 인터넷 기술에 대해 덜 만족하며, 스트레스를 받는 상황을 더 많이 경험하게 된다. 이렇게 인터넷 초보자가 견는 인터넷 이용의 복잡함에 대한 편견과 초 기 적응에 대한 지식장벽들은 자기효능감이 부 족하기 때문이다(Eastin and LaRose 2000).

또한 사용자들의 인지적 전랴, 특히 정보처리 기술이 인터넷에서의 성공적인 탐색을 결정하 기 때문에 (MacGregor 1999), 온라인 쇼핑몰과 같은 웹기반 환경을 이용할 때 개인의 인터넷 자기효능감 수준에 따라서 정보탐색 및 행동에 미치는 영향이 다를 수 있다.

실제로 인터넷 자기효능감이 높을수록 과제 수행 능력이 뛰어나다는 것을 확인한 몇 몇 연 구들이 있다. Nahl(1996)은 인터넷 자기효능감 과 학생들의 인터넷 실습 프로그램에 대한 태 도의 관계를 검증하였는데, 인터넷 자기효능감 이 낮은 학생들이 관련과목 수강을 중도에 포 기한 경우가 많았으며. 일상적인 과제 수행에 있어서도 인터넷 자가효능감이 높은 학생들이 더 효율적으로 과제를 수행하였다. 자기효능감 지각이 업무 성과(Nahl 1996, 1997)와 사용정 도(Ren 1999)와 긍정적 관계가 있다. 또한 인 터넷 자기호능감은 이전 인터넷 사용경험, 결과 기대, 그리고 인터넷 사용과 긍정적 상관관계가 있는 반면 인터넷에 대한 스트레스와 자기경멸 과는 부정적인 관계가 있다(Eastin and LaRose 2000). Tsai and Tsai(2003)는 웹 기반 과학 학 습활동에서 정보 탐색 전략에 대한 학생들의 인터넷 자기효능감의 영향력을 검증하였는데 
높은 자기효능감을 가진 학생들이 더 우수한 정보탐색 전략을 이용해서 과제를 수행한다는 것을 알아냈다

Hsu and Chiu(2004)에서는 인터넷 자기효능 감이 e-service를 이용하기 위한 노력에 있어 중요한 변수임을 제안하며. 인터넷 자기효능감 을 일반적인 인터넷 자기효능감과 특정 웹에서 의(web-specific) 인터넷 자기효능감으로 나누 었으며 Ajzen(2002)의 확장된 계획적 행동이론 을 적용하여 일반적인 인터넷 자기효능감이 태 도에 미치는 긍정적인 영향과 특정 웹에서의 인터넷 자기효능감의 e-service 사용의도와 e-service 사용에 대한 긍정적인 영향을 검증하였다.

본 연구는 자기효능감의 특성에 근거하여 인 터넷 이용이라는 포괄적인 개념이 아닌 인터넷 을 이용한 구매상황에서 정보탐색 능력에 대한 소비자 스스로 지각한 능력으로 인터넷 자기효 능감(browsing self-efficacy)을 제한적으로 사 용하려고 한다. 이것은 플로우의 선행변수의 하 나로 언급되는 숙련도(skill) 과는 구별되는 개념 이다. 즉 숙련도는 기술로서 인터넷 사용능력. 관련지식, 능숙함 등의 행위능력으로 정의되는 데(유상진, 최은빈, 김효정 2006), 이 숙련도는 나름대로 객관적으로 입증된 기술능력이라고 볼 수 있는 반면, 자기혀능감은 사용자 자신이 스스로 느끼는 주관적인 자신감이라고 볼 수 있습니다. 인터넷 정보탐색 활동은 웹 브라우징 (web browsing), 웹 서핑 (web surfing), 인터 넷 항해(navigation) 라고도 하며(박철 2000), 인 터넷 상에서의 브라우징은 소비자가 웹 사이트 를 방문하여 웹 컨텐츠를 읽거나 보거나 듣는 행위를 의미한다. 따라서 인터넷 자기효능감이 란 '인터넷 상에서 브라우징을 수행할 수 있다
는 개인의 능력에 대한 판단이다.

인터넷을 이용하여 구매목적을 가지고 또는 구매와 상관없이 제품정보를 탐색할 때 개인의 인터넷 자기효능감에 따라 정보탐색 용이성이 나 탐색정보량 또는 정보탐색정보의 질이 달라 질 것이다. 인터넷 자기효능감이 높은 사람은 그렇지 않은 사람보다 정보탐색을 더 쉅게 할 것이며, 더 많은 정보를 더 빠른 시간 안에 찾 을 수 있을 것이며, 정보의 양 뿐만 아니라 자 신이 찾고자 하는 제품의 정보를 정확히 찾아 낼 수 있을 것이다.

현재 인터넷은 양방향의 소비자정보 수집과 활용이 가능하여 소비자에게 무한한 정보를 제 공해주고 있으며, 인터넷 소비자 정보 사이트에 서는 소비자들을 위해 가장 기본이 되는 생활 정보에서부터 제품이나 서비스의 품질 및 가격. 제품의 장단점, 각종 특성 비교, 피해구제나 피 해예방 정보, 법률정보 등 많은 소비자정보들을 제공하고 있다. 그러나 Jarvenpaa and Todd (1997)에 의하면 실제로 소비자가 인터넷 쇼핑 몰을 적극적으로 활용하지 못하는 이유는 제품 을 찾기 위한 인터넷 항해의 어려움 때문이라 고 하였다. 소비자는 인터넷에서 제품을 구매하 는 의사결정을 내릴 때 불확실성을 감소시켜 줄 수 있는 정보를 필요로 하며. 인터넷 자기효 능감이 높을수록 자신이 인터넷 쇼핑을 할 때 필요한 능력을 갖추었다고 생각하고, 더 많은 유용한 제품정보를 검색해서 얻을 수 있다는 자신감을 가질 것이다.

\section{2 인터넷 쇼핑에서 플로우 연구}

Csikszentmihalyi(1977)는 플로우를 "사람이 
전체적으로 관여되어 행동할 때 느끼는 푹 빠진 감정(holistic sensation)"이며 즐거움(playfuiness) 의 의미를 형상화하고 확장한 것이라고 하였다 (Csikszentmihalyi 1977; Csikszentmihalyi and LeFevre 1989), 즉 플로우란 행동 그 자체에 흥미를 느껴 외부의 보상이 없더라도 지속되는 행동을 통해 얻는 경험으로 시간. 공간 개념을 의식하지 않고 활동자체에 몰두하다보면 모든 것이 자연스럽게 흐르는 듯한 느낌을 갖게 되는 상태를 말하는데, Hoffman and Novak (1996) 이 이 개념을 인터넷에 적용한 후 인터넷 이용 환경에서 중오한 변수로서 플로우 관련 연구가 활발하게 이루어지고 있다. 플로우에 대한 기존 주요연구에서 밝혀진 플로우의 구성개념 및 관 련변수들을 요약하면〈표 1)과 같다. 표에서 보 는 바와 같이 Novak, Hoffman, 그리고 Yung (1998)은 기존 플로우연구의 모든 관련변수를 제시하고 있다.

인터넷상에서 플로우 상태의 특징은 다음과 같다. 플로우 상태에 있는 소비자는 첫째, 인터 넷과 상호작용을 통해 피드벅을 경험하고 이를 스스로 통제한다는 느낌을 갖게 되는 상태이며.
둘째, 인터넷 활동 자체가 놀이를 하고 있는 것 처럼 즐겁고. 셋째, 인터넷에서의 행동들에 대 해 사용자의 신분 노출이 되지 않기 때문에 사 회적인 자의식(self-consciousness)을 잊고 몰두 하게 되고, 넷째, 인터넷 항해 활동 그 자체에 흥미를 느껴 내재적인 보상을 갖게 되어, 외부 적인 보상이 없어도 스스로 지속적으로 인터넷 에 집중하고 머물게 되는 상태를 의미한다.

마케팅 측면에서 플로우는 즐거움을 통한 몰 입 행동이며 즐거움을 느끼는 최적의 경험은 긍정적인 감정을 유발하게 되어서 소비자의 긍 정적 행동을 유도할 수 있다. 따라서 전자상거 래에 있어 플로우가 중요한 핵심변수가 될 수 있으며 플로우의 개념을 중심으로 소비자 행동 모형을 형성하고, 인터넷 사용자들이 경험하는 플로우 경험에 대해 모형을 수정하고 이를 검 증하는 과정을 통해서 플로우를 측정하고 모형 화하는 연구로 발전되었다(Novak and Hoffman 1997: Novak, Hoffman, and Yung 1998, 2000; 김종호 신용섭 2004).

Mannell et al.(1988)은 플로우는 행위자가 자 신의 행위에 대해 완전히 관여하는 것이라 하

〈표 1) 주요연구의 플로우(flow) 구성개념 및 변수들

\begin{tabular}{|c|c|c|c|c|c|c|c|c|c|c|c|c|c|}
\hline 관련 논문 & $\begin{array}{l}\text { 기 } \\
\text { 술 }\end{array}$ & $\begin{array}{l}\text { 도 } \\
\text { 전 }\end{array}$ & $\begin{array}{l}\text { 각 } \\
\text { 성 }\end{array}$ & $\begin{array}{l}\text { 통 } \\
\text { 제 }\end{array}$ & $\begin{array}{l}\text { 탐 } \\
\text { 색 } \\
\text { 적 } \\
\text { 행 } \\
\text { 동 }\end{array}$ & $\begin{array}{l}\text { 주 } \\
\text { 의 } \\
\text { 집 } \\
\text { 중 }\end{array}$ & $\begin{array}{l}\text { 상 } \\
\text { 호 } \\
\text { 작 } \\
\text { 용 }\end{array}$ & $\begin{array}{l}\text { 관 } \\
\text { 여 } \\
\text { 도 }\end{array}$ & $\begin{array}{l}\text { 최 } \\
\text { 적 } \\
\text { 자 } \\
\text { 극 } \\
\text { 수 } \\
\text { 준 }\end{array}$ & $\begin{array}{l}\text { 즐 } \\
\text { 거 } \\
\text { 움 }\end{array}$ & $\begin{array}{l}\text { 긍 } \\
\text { 정 } \\
\text { 적 } \\
\text { 감 } \\
\text { 정 }\end{array}$ & $\begin{array}{l}\text { 텔 } \\
\text { 레 } \\
\text { 프 } \\
\text { 레 } \\
\text { 젠 } \\
\text { 스 }\end{array}$ & $\begin{array}{l}\text { 시 } \\
\text { 간 } \\
\text { 왜 } \\
\text { 곡 }\end{array}$ \\
\hline Csikszentmihalyi(1977) & & & & 0 & & $\mathrm{O}$ & $\mathrm{O}$ & $\mathrm{O}$ & & & & & \\
\hline Mannell, Jiri.\& Lason(1988) & O & $\mathrm{O}$ & & $\mathrm{O}$ & & 0 & & $\mathrm{O}$ & & & 0 & & \\
\hline Hoffman \& Novak(1996) & $\mathrm{O}$ & $\mathrm{O}$ & & & & 0 & 0 & & $\mathrm{O}$ & & & $\mathrm{O}$ & $\mathrm{O}$ \\
\hline Novak, Hoffman, \& Yung(1998) & $\mathrm{O}$ & $\mathrm{O}$ & 0 & 0 & 0 & $\mathrm{O}$ & $\mathrm{O}$ & $\mathrm{O}$ & $\mathrm{O}$ & $\mathrm{O}$ & 0 & 0 & $\mathrm{O}$ \\
\hline
\end{tabular}

자료원: 유성진, 최은빈. 김효정(2006)에서 발췌 
였으며, 목적이나 행위 등과 같은 사건에 깊이 관여되어 있는 사람들에 의해 경험되고, 이들 은 여기서 완전히 푹 빠지게 되고 이 때, 시간 은 정지되어 있는 것처럼 보이며, 다른 것들은 신경 쓰지 않게 된다(Lutz and Guiry 1994). Trevino and Webster(1992)는 통제. 주의집 중, 호기심, 내재적 흥미의 네 가지 특성이 종 합된 선형적 변수로 폴로우에 대한 조작적 정 의를 내리고 있다. 그러나 이러한 네 특성이 어떻게 사용되는지, 선행변수인지 결과 변수 인지 정확히 정의내리지 못하고 있다. 이에 반해 Csikszentmihalyi and Csikszentmihalyi (1988)는 개인의 숙련도(skill)와 행동에 대한 도전감(challenge)의 지각이 균형을 이루어야 하고 이들은 일정 수준 이상으로 모두 충족되 어야 함에 초점을 맞추고 있다. 이들의 연구는 기술과 도전감이 모두 높아야 한다고 지적하 여, 숙련도와 도전감이 모두 낮을 때도 플로우 를 느낄 수 있다는 Csikszentmihalyi(1977)의 연구와 다른 점을 보였다.

Hoffman and Novak(1997)은 인터넷 전자상 거래라는 구체적 상황을 설정해서 이러한 환경 에서 소비자의 구매결정에 영향을 주는 요인으 로 플로우가 작용하는지에 대한 확장 연구를 시도하였다. 김명소(1999)는 Novak, Hoffman, and Yung(1998)이 제시한 플로우 모형에서 궁 극적인 구매의도와 온라인 쇼핑몰 이용의도라 는 종속변수까지 확대하여 전자상거래 이용의 도에 플로우가 긍정적 요인으로 작용한다는 결 과를 얻었다. 또한 한상린, 박천교(2000)도 플 로우의 개념을 이용해 인터넷 환경 하에서 소 비자 구매의도 결정요인을 분석하였는데, 소비 자의 플로우 수준이 관여도를 통해 간접적인
영향요인으로 작용하였지만 직접적으로 구매의 도에 미치는 유의한 영향은 밝히지 못하였다. 이건창, 정남호(2000)는 인터넷 쇼핑몰에 대해 가상현실 기법을 적용하여 플로우의 핵심 요인 이 되는 실재감과 몰입감을 충족시켜 주기 위해 VRISA라는 가상현실 기법을 적용한 인터넷 쇼핑몰을 구현하여 소비자의 구매의도에 미치 는 영향을 분석하였는데 상호작용성, 3 차원 그 래픽, 몰입감을 충족시켜주어 가상현실을 적용 한 인터넷 쇼핑몰 VRISA는 기존 인터넷 쇼핑 몰보다 2배 정도 구매의도를 증진시킨다는 것 을 밝혀냈다. 이는 실제 소비자들이 플로우 개 념이 적용된 쇼핑몰에서 높은 구매의도를 보인 다는 것을 밝혀낸 연구라는 점에서 의의가 있다. 이명수, 박종희, 김도일(2001)은 인터넷상에서 지각된 플로우와 실용적 가치가 구매의도에 긍 정적인 영향을 미친다는 것을 알아냈다. 이때 플로우의 선행변수인 도전감, 숙련도, 상호작용 성중에서 도전감과 숙련도만 플로우에 긍정적 인 영향을 미치는 것을 알아냈다. 한편 Novak. Hoffman, and Yung (1998)은 상호작용성의 3 차원인 속도, 매핑(mapping), 범위를 대상으로 상호작용성을 측정하고 이에 대한 폴로우의 영 향관계를 연구하였는데. 속도만이 유의성을 나 타내며 이용환경의 속도가 플로우상태의 경험 예 유의적인 영향을 미치는 것을 검증하였다.

플로우의 결과변수로 나타나는 탐색행동의 증 가가 실질적으로 인터넷 전자상거래 시장 하에서 구매의도와 직접적인 관계에 대한 연구도 이루 어졌는데, Novak, Hoffman, and Yung (1998) 은 웹 기반의 온라인 환경 하에서 플로우상태 가 긍정적인 정서를 유발하고 탐색행동을 증가 시키는 결과를 가져오는 것을 연구하였고, 성영 
신, 박은아, 이성수(1998)의 연구에서도 이러한 긍정적인 정서와 탐색행동 증가가 인터넷 쇼핑 몰 사이트에 대한 재방문과 거래관계 지속 의 도를 증가시켜 직접적인 궁극적 종속변수로서 구매의도에 연결될 수 있음을 보여주었다. 두정 완(2003)은 플로우와 소비자 구매의도 관계와 플로우 유형에 따른 구매행동 차이 분석에서 인터넷 환경과 이용자의 상호작용성은 이용자 의 웹 이용관련 숙련도의 지각과 도전감의 지 각의 균형은 인터넷 환경에 대한 긍정적 감정 과 이용기대에 긍정적인 영항을 미치며, 이용기 대는 인터넷환경에서의 소비자의 제품 구매의 도에 긍정적인 영향을 미칠 것이라 하였지만 플로우와 구매의도와 작접적인 영향은 확인하지 못했다.

그 밖에 이시훈 $(2000)$ 은 일반 인터넷 사용자 를 대상으로 인구통계학적 톡성에 따른 플로우 경험의 차이와 인터넷 광고 효과와 폴로우 경 험과의 관계를 분석하였다. 인터넷 이용자를 연 령과 소득, 학력. 인터넷 이용기간, 인터넷 사용 환경 등에 따라 그들의 플로우 경험에 있어서 의 차이를 파악하려 하였으나. 결과적으로 인구 통계학적 특성을 파악해 내지 못했다. 또, 예종 석, 김동욱 $(2003)$ 은 플로우의 부정적 측면에 관 한 연구로 인터넷 중독에 영향을 미치는 선행 요인을 이용-충족 접근법에 따라 폴로우 등의 개인적 성향이 인터넷 중독에 미치는 영향에 관한 연구가 있다.

\section{3 인터넷 쇼핑에서 지각된 위험(perceived risk) 대한 연구}

소비자 행동에서 위험이란 현실적 또는 객관
적으로 존재하는 위험이 아니라 소비자가 선택 상황에서 주관적으로 지각하는 위험 즉. '지각 된 위험(perceived risk)'을 의미한다. 따라서 현 실적으로 위험이 존재하더라도 소비자가 그 위 험을 주관적으로 지각할 때만 그 위험은 문제 가 된다. 지각된 위험은 소비자가 특정 구매목 적을 달성하기 위해 브랜드 선택, 점포선택, 구 매방식 선택 등을 행하고자 할 때 그 선택상황 에 대해 지각하는 심리적인 위험을 포함한다 (Bauer 1960). Bauer(1960)는 지각된 위험을 "소비자의 어떤 행동이 확실하게 예측할 수 없 는 결과를 초래할 가능성”이라고 정의하고 있 으며 이러한 정의는 '불확실성(uncertainty)' 과 '불리한 결과(consequence)'라는 개념이 포함되 어 있다.

지각된 위험과 관련 연구(Bettman 1973: Cox 1967; Cunningham 1967; Peter and Ryan 1976)들을 살펴보면. 소비자가 주관적으로 느끼 는 결과에 대한 '불확실성(uncertainty)'과 '중 요성(importance)'이라는 두 가지 공통 요소를 확인할 수 있다. $\operatorname{Cox}(1967)$ 는 지각된 위험의 크기는 구매행동의 결과가 바람직하지 못할 것 이라는 주관적 확실성의 정도와 이때 발생하게 될 부담의 정도(amount of stake)에 의해서 결 정된다고 하였다. 이 때 부담의 정도는 구매목 적의 중요성, 구매목적이 달성되지 못할 때 치 를 희생의 정도, 그리고 구매목적의 달성에 소 요된 수단의 크기에 따라 결정된다.

Akaah and Korgaonkar(1988)의 연구에 따르 면, 점포소매점보다는 무점포 소매점에서의 구 매가 더 높은 위험 수준을 보이며, $\operatorname{Tan}(1999)$ 은 인터넷 쇼핑에서 소비자들이 지각하는 위험 수준이 일반 오프라인 점포에서의 위험 수준보 
다 높게 나타난다고 하였다. 실제로 인터넷이 상호작용성이 뛰어난 매체라고 하더라도, 판매 원과의 상담, 실물과의 비교, 실재감, 시용과 같 은 오프라인에서 제공하는 다양한 정보를 제공 하기 어렵기 때문에 소비자들이 인터넷 쇼핑몰 에서의 구매에 있어 위험을 지각할 수밖에 없 다고 지적되고 있다. 이와 같이 인터넷 쇼핑에 서 구매행동할 때 소비자의 지각된 위험은 지 대한 영향을 미친다. 지각된 위험 요인들은 인 터넷 쇼핑몰에서의 구매의사결정의 결과에 대 하여 적지 않은 거래 위축을 가져오며(박유식. 한명희 2001), 따라서 이러한 지각된 위험을 낮 추는 것이 필요하며 중요하다(Burke 1997).

인터넷쇼핑과 관련하여 이용자가 지각하게 되 는 위험요인으로는 경제적 위헙, 사회적 위험, 성과 위헙, 개인적 위험, 프라이버시 위험 등이 있으며, 인터넷 쇼핑몰에서 구매하는 상황에 있 어서는 신용카드 번호, 개인신상정보와 관련된 프라이버시 위험이 특히 중요한 위험유형으로 제안되고 있다(Jarvenpaa and Todd 1997). McCarthy(1997)는 인터넷 기반 전자상거래에 서 가능한 시스템과 네트워크 보안 및 시스템 불안과 관련된 위험요인이 있다고 제시하였는 데, 사고 및 악의에 의한 웹 사이트에서 자료손 실 위험. 부적절한 통신을 하는 지역단위 웹 서 비스의 확산은 시스템에 피해를 입힐 수 있는 위험, 웹 전송 및 수신 측에 대한 데이터 변경 위험, 의도적 부정확한 표현 및 자료 오용에 대 한 위험, 온라인 주문 및 거래 발생 이후 사실 을 부인할 수 있는 위험, 부주의함에서 오는 오 용의 위험, 데이터의 무단변경 및 수신의 위험, 불법적 전자상거래의 위험, 무단 공시의 위험이 있다고 하였다.
김종호, 신용섭(2000)은 소비자의 위험지각에 영향을 미치는 변수로 복잡성, 기업명성, 보안 성을 제시하였고, 박유식, 한명희(2001)는 인터 넷 쇼핑몰에서 위험지각과 품질지각이 구매의 도에 미치는 영향과 쇼핑몰 제공 보증과 정보 의 양이 위험지각과 품질지각에 미치는 영향을 조사하였으며, 전성률, 허종호, 강석준(2003)은 위험유형을 크게 제품위힘(perceived product risk) 과 거래위험(perceived transaction risk)으 로 구분하여 인터넷 쇼핑에서의 구매의도에 미 치는 영항을 살펴보았는데 두 위험 모두 구매 의도에 부정적인 영향을 주는 것을 발견하였다.

지각된 위험은 소비자들의 구매의도를 향상시 키기 위해 관리되어야 하며 이에 따라 지각된 위험을 낮추는 방안에 대한 연구들도 이루어졌 다. Roselius(1971)는 위험(손실)을 시간손실, 위해손실, 자아손실, 금전손실로 나누었는데, 4 가지 위험 모두 상표애호도 또는 좋은 상표이 미지를 이용해서 위험을 낮추는 방법이 가장 선호되었고 구전 활용이 두 번째로 선호되었다. Sheth and Venkatesan(1968)은 충분한 정보탐 색, 구매 전 숙고(prepurchase deliberation), 상 표이미지 또는 상표애호도, 실제구매 경험을 통해서 위험을 감소한다고 주장하였다. 오프라 인 상에서의 지각된 위험 감소행동 연구가 온 라인 상에서의 지각된 위험 감소 행동과 유의 한 관련성이 있으며, 전성률, 허종호, 강석준 (2003)의 연구에서는 거래위험, 제품위험이 상 표. 가격의 상대적 중요도에 미치는 영향을 연 구하고 이러한 거래위험과 제품위험이 인터넷 쇼평몰의 안정성이나 명성에 의해 감소할 수 있다고 하였다. 


\section{III. 연구모형과 가설설정}

\section{1 연구모형}

〈그림 1〉에서 제시된 연구모형은 인터넷 쇼핑 시 인터넷 자기효능감이 높을수록 플로우를 더 경험할 것이고 플로우가 높을수록 웹사이트 태도 는 호의적일 것이고 또한 인터넷 자기효능감이 높을수록 지각된 위험이 낮아지며, 지각된 위험이 낮을수록 웹사이트 태도는 호의적일 것이다. 그리 고 웹사이트 태도가 호의적일 수록 구매의도는 높아질 것이라고 제안한다. 또 지각된 위험이 낮 을수록 플로우를 더 경험할 것이라고 제안한다.

\section{2 가설설정}

\subsection{1 인터넷 자기효능감이 플로우(flow),} 지각된 위험에 미치는 영향

자기효능감은 개인이 스스로의 행동수행능력
에 대해 갖는 신념이며, 사람들이 주어진 상황 을 통제하기 위해 노력을 할 것인지의 여부는 자신이 통제할 수 있을 지에 대한 신념에 따라 달라진다(Bandura 1997). 사회인지이론에 따르 면. 자기 효능감의 발달을 통해 내재적 흥미 (intrinsic interest)가 고양된다고 한다. 사람들 은 자신이 효율적이라고 느끼는 활동과 자기만 족감을 주는 활동에 지속적인 흥미를 보이는데, 대부분의 활동을 할 때 행동 그 자체나 자연적 피드백은 본질적으로는 보상이 되지 못한다. 그 러나 행동 자체가 보상이 되지 않더라도 그 행 동에 개인적인 중요성을 부여하면 행동은 보상 을 제공할 수 있기 때문에 일단 개인적인 중요 성을 부여한 활동에 스스로 관여하면 수행 달 성에 따라 자기만족적이거나 불만족적인 반응 들을 유발하게 된다.

Csikszentmihalyi(1977)는 지각된 능력에 부합 되고 수행향상에 대한 피드백을 주는 도전을 선택하면 대부분의 활동에서 내재적 흥미가 유 발될 수 있다는 것을 발견하였다. Malone(1981) 은 개인적으로 도전 목표를 정하여 활동을 수

〈그림 1〉 연구모형

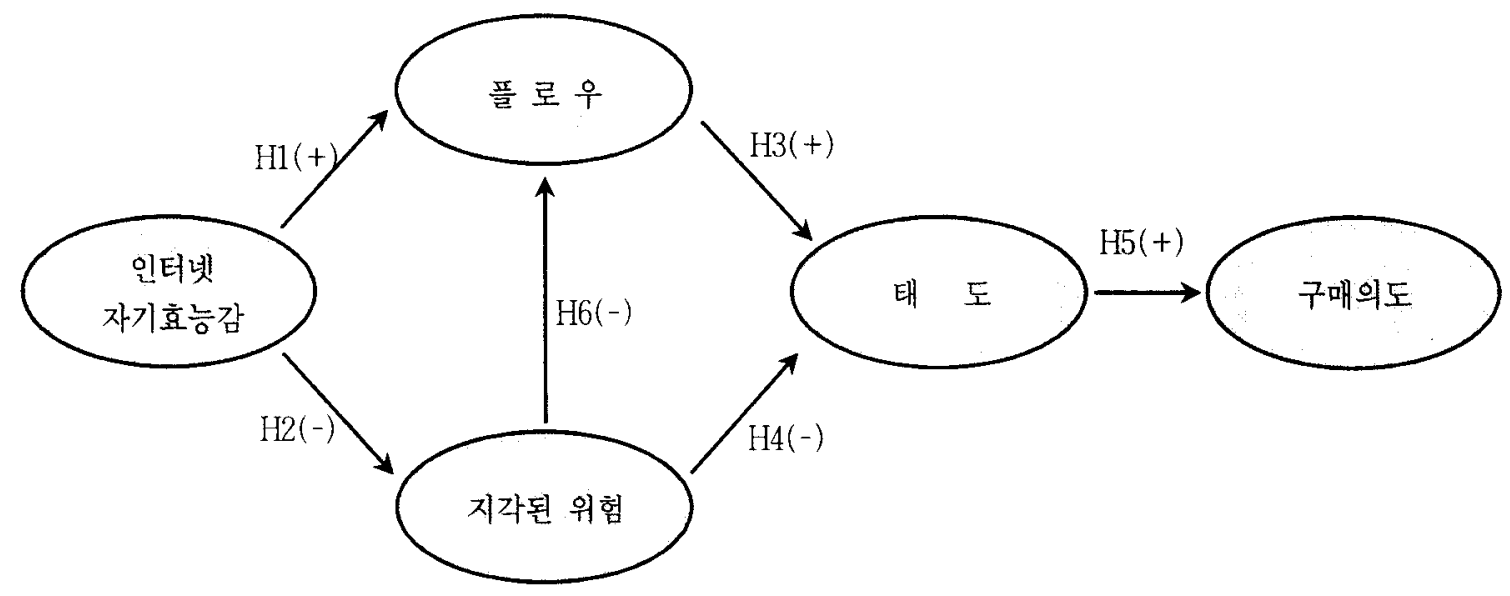


행하는 것은 지속적인 주의를 유발할 수 있다 고 하였다. 개인이 어떤 과업을 수행하려는 의 지를 갖고 이를 숙달할 때 사람들은 만족감을 느끼며, 목표달성을 통해 얻어진 만족은 내재적 흥미를 유발하게 되는 것이다. 또한 숙달해야하 는 과제에 대해 자기효능감이 있으면 그 과제 를 수행을 할 때 쉽게 흥미가 유발되고(Bandura 1997), 자기효능감이 높은 학생들일수록 스스로 더 높은 학업적 도전을 설정하여 학문분야에 대한 내재적 흥미를 증가시킨다고 한다(Pintrich and DeGroot 1990).

이러한 맥락에서 볼 때 기존 전통적인 오프라 인 상에서의 인터넷 자기효능감이 인터넷상에 서도 적용될 수 있다고 판단해서, 정보탐색을 효과적으로 수행하기 위해 요구되는 능력에 대 한 신념인 인터넷 자기효능감이 높을수록 소비 자는 인터넷 정보탐색을 할 때 더 높은 도전을 설정하고 목표달성을 통해 만족을 얻어 내재적 흥미가 유발될 것이다. 따라서 소비자의 인터넷 자기효능감이 높을수록 인터넷 이용 시에 플로 우를 더 경험할 것이다.

가설 1: 인터넷 자기효능감이 높을수록 플로 우를 더 경험할 것이다.

사회인지이론에서 두려움(anxiety) 과 회피행 동을 야기시키는 것은 주로 잠재적인 위협에 대처할 때 갖는 비효능감(inefficacy)이라고 한 다(Bandura 1986). 사람들은 혐오적일 수 있는 상황과 활동을 회피하는데 그 이유는 두렵기 때문이 아니라 그들이 위험한 측면을 다룰 수 없을 것이라고 믿기 때문이다. 따라서 위협을 다루는 데 있어 스스로 효능적이라고 판단한
사람들은 위험한 측면을 두려워하지도 않고 회 피하지도 않지만 스스로 잠재적 위협에 비효능 적이라고 인식하는 사람들은 부정적 결과를 초 래할 것이라고 상상하기 때문에 위험한 측면을 회피하려고 한다. Compeau and Higgins(1995) 는 컴퓨터 자기효능감이 두려움(anxiety)에 미 치는 유의적인 영향을 발견하였는데, 개인의 컴 퓨터 자기효능감이 높을수록 컴퓨터에 대한 두 려움이 낮아지는 것을 확인하였다.

소비자들은 인터넷 쇼핑몰에서 제품을 실제로 확인할 수 없고 가격이나 품질 비교를 할 때 전통적인 소매점에 비해 용이하지 않다는 위험 을 느껴서 인터넷 쇼팡몰에서 구매하기를 꺼리 고 있으며(Dennis 1998), Strader and Shaw (1997)는 인터넷 쇼핑몰에서는 화면상에 나타 난 제품 및 판매자에 관한 정보만을 가지고 제 품을 구매하기 때문에 소비자가 직접 판매자를 선택하고 제품을 눈으로 확인한 후 구매하는 전통적 유통경로에 비해 제품의 품질이나 판매 자 불신, 개인정보 유출과 관련된 불안감이 높 아질 것이라고 하였다.

이러한 상황에서 소비자의 제품지식이 많을수 록, 소비자의 인터넷 사용능력이 높을수록, 소 비자의 인터넷 사용에 대한 도전의식이 높을수 록, 인터넷올 이용하여 정보탐색을 할 가능성이 상대적으로 높다(문병준, 손용석 2000).

이와 같은 맥락에서 소비자의 인터넷 자기효 능감이 높을수록 제품정보에 대한 탐색을 잘 할 수 있다는 자신감을 가지고 제품관련 정보 를 탐색할 것이다.

따라서 구매의사결정에 영향을 미치는 위험은 실제로 존재하는 위험이 아닌 개인이 지각하는 위험으로 소비자 스스로가 인터넷 사용 능력이 
높다고 인식할수록 인터넷 쇼평 시에 지각하게 되는 위험이 낮아질 것으로 생각할 수 있다.

가설 2: 인터넷 자기효능감이 높을수록 지각 된 위험은 낮을 것이다.

3.2 .2 플로우(flow)와 지각된 위험이 태도 에 미치는 영향과 태도가 구매의도에 미치는 영향

플로우(Flow)이론에 따르면 플로우의 경험은 특정 활동을 수행할 중요한 이유가 되는데 (Csikszentmihalyi 1977), 특정 활동을 좋게 느 낀다면 그것은 본질적으로 동기를 유발시키고 사람들은 그 활동과 관련이 있는 활동을 할 가 능성이 높아진다는 것이다. 따라서 플로우는 반 복경험을 이끌게 된다. 따라서 Hoffman and Novak(1996)은 웹사이트의 반복적인 방문과 인터넷에서의 구매의도 증대를 위해 플로우를 용이하게 해야 한다고 주장하였다. 즉 웹사이트 를 항해하는 동안 즐거움을 느끼게 되면 그 사 이트를 반복적으로 방문하계 되고 이는 인터넷 구매의도를 증대시킬 수 있다고 하였다. Novak. Hoffman, and Yung (1998)은 플로우 모형에 서 플로우의 결과변수로 긍정적 감정(positive affect)을 제시하고 있다. Zajonc and Markus (1982)의 단순노출효과에 따르면 동일한 대상 을 여러 차례 접하게 되면 따뜻한 느낌. 소유 감. 혹은 친근감을 가지게 되며, 그 대상에 대 한 호감(liking)을 갖게 된다고 하였는대, 이러 한 맥락에서 소비자가 인터넷 검색동안 특정 웹사이트에 긍정적 감정을 느끼게 되면 그 웹
사이트를 더 이용하게 될 것이며 특정 웹사이 트에 대한 반복적인 방문으로 친근감을 형성하 고 이러한 친근감이 특정 웹사이트에 호의적인 태도를 형성할 수 있을 것이다.

가설 3: 소비자가 플로우를 더 경험할수록 웹 사이트 태도는 호의적일 것이다.

소비자의 지각된 위험은 구매의도와 부정적인 관계를 가진다는 사실은 여러 선행연구에서 밝 혀졌다. Jarvenpaa and Todd(1997)에 의하면. 인터넷 쇼핑에 대한 구매의도는 제품가치, 쇼핑 경험, 서비스 품질, 그리고 지각된 위험의 4 가 지 요인에 의해 영향을 받으며, 이중 지각된 위 험이 높을수록 구매의도는 낮아진다고 하였다. 지각된 위험이 높을수록 소비자는 구매행동을 연기시키거나 회피할 가능성이 높아진다고 하 였다(Sheth and Venkatesan 1968; Roselius 1971). Peter and Ryan(1976)은 지각된 위험이 제품선택 또는 구매로 인하여 발생되는 기대손 실의 관점에서 구매를 방해하는 부정적인 요인 이라고 하였고, 전성률, 허종호, 강석준(2003)도 온라인 쇼푕몰 이용에 있어서의 지각된 위험인 제품위험과 거래위험이 온라인 구매의도에 부 정적인 영향을 미친다고 하였다.

이상의 선행연구들을 종합하면 인터넷을 이 용한 구매에 대한 지각된 위험이 높아지면 인 터넷 쇼핑 구매의도는 낮아진다고 할 수 있는 데, 많은 인터넷 관련 연구자들이 구매위험지 각이 인터넷에서의 구매를 방해한다고 주장하 고 있다(Burke 1997; Guelch and Klein 1996). 그러나 다른 실증연구에서는 위험지각이 구매 의도에 영향을 미치지 않는 것으로 나타나거나 
(Jarvenpaa and Todd 1997), 단지 관련이 있을 것이라 시사하기도 한다(김상용, 박성용 1999). 이러한 점에서 지각된 위험을 구매제품과 관련 된 위험 신념의 관점에서 유추해 보면 소비자 의 대안평가과정이 평가기준에 근거한 신념에 의해 형성된 태도로부터 구매의도가 형성되는 과정이라는 점에서 선택 안에 대한 지각된 위 험은 태도와 구매의도에 영향을 미친다고 볼 수 있다. 따라서 인터넷 쇼핑 시 지각된 위험은 소비자가 이용하는 웹사이트 태도에 負(-)의 영향을 미칠 것이라 생각할 수 있다. 따라서 소 비자가 인터넷 쇼핑에 대한 위험을 낮게 지각 할수록 웹사이트 태도는 호의적일 것이다.

가설 4: 지각된 위험이 낮을수록 웹사이트 태 도는 호의적일 것이다.

Fishbein and Ajzen(1975)에 따르면 태도는 행 동의도의 직전 선행 변수이며, 이는 어떠한 대상 에 호의적인 태도를 가질수록 그 대상(제품, 브 랜드)을 구매할 의도가 높아지는 것을 의미한다. 이와 마찬가지로 본 연구에서 웹사이트에 대한 태도는 소비자가 특정 웹사이트를 이용할 때 웹 사이트에 대한 호의적인 태도를 가질수록 그 웹 사이트에서 구매할 의도가 높아질 것이다.

가설 5: 웹사이트 태도가 호의적일수록 구매 의도는 높아질 것이다.

\subsection{3 지각된 위험이 플로우(flow)에 미치는 영향}

컴퓨터 두려움(computer anxiety)이란 현재
및 미래의 컴퓨터 사용에 대해 두려워하고 우 려하며, 쉽지 않다고 생각하는 개인의 경향이다 (Parasuraman and Igbaria 1990). MS 분야에 서는 컴퓨터라는 새로운 매체와 사용자와의 상 호작용에 있어서 사용자가 컴퓨터에 대해 가지 는 두려움(anxiety)을 연구해왔다(Webster and Martocchio 1992). 일반적으로, 두려움의 수준 이 높은 사람은 상대적으로 낮은 수준의 사람 보다 기계에 대한 두려움을 많이 나타내며 컴 퓨터 또한 그러한 사람들에게는 공포의 원천이 될 수 있다(Turkle 1984). 또한 Webster and Martocchio(1992)는 컴퓨터 상호작용에서 자발 적 흥미(playfulness)와 컴퓨터 두려움과 부정 적인 관계가 있다고 하였으며, Bozionelos(1997) 는 인지적 자발성(cognitive spontaneity)과 컴 퓨터에 대한 두려움의 부정적 상관관계를 연구 하였다. Woszczynski, Roth, and Segars(2002) 도 Webster and Martocchio(1992)의 연구에 기반하여 컴퓨터 두려움이 낮은 개인은 컴퓨터 와 상호작용하는 스트레스가 많은 상황에서 침 착함을 유지하며 새로운 컴퓨터와의 상호작용 을 시도할 때 어려움을 덜 격고 컴퓨터와의 상 호작용을 더 쉽게 생각한다고 하뎌 컴퓨터 두려 움은 플로우 상태와 즐거운 행동(playful behavior) 에 부정적 영향을 미친다는 것을 밝혀냈다.

이러한 컴퓨터 두려움과 관련된 맥락에서 인 터넷을 이용하여 제품구매하는 것에 대한 지각 된 위험이 높을수록 인터넷 쇼핑에 대한 긍정 적 경험을 하기 힘들 것이고 즐거움이나 자발 적 흥미를 경헙하기 힘들 것이다.

가설 6: 지각된 위험이 낮을수록 플로우를 더 경험할 것이다. 


\section{IV. 연구방법}

\section{1 자료수집방법과 대상}

본 연구의 실증조사에 사용되는 인터넷 쇼핑 몰을 선정하기 위해 사전조사를 실시하였다. 대 학생 및 대학원생으로 구성된 58 명의 예비표본 을 이용해서 유명 쇼평몰 중 정보탐색을 해보 거나 제품을 구매해 본 적이 있는 쇼핑몰을 중 복선택하게 한 결과 인터파크(www.interpark.com) 가 가장 많이 선정되었고(32명/58명), 실제로 인터파크는 GS eshop과 함께 인터넷 쇼핑몰 업계 1 위로 가장 많이 알려져 있는 쇼핑몰로 퐌단되어 본 연구의 인터넷 쇼핑몰 사이트로 선정하였다.

본 연구를 위해 설문지를 사용하여 데이터를
수집하였다. 자료수집대상은 인터파크를 이용한 경험이 있는 대학생 193명을 대상으로 설문조 사를 실시한 후 불성실한 응답을 한 2 명을 제 외하고 191 명의 설문응답을 이용해서 분석을 실시하였다.

\section{2 연구개념의 조작적 정의 및 측정}

\subsection{1 인터넷 자기효능감}

인터넷 자기효능감에 대한 측정(measure)은 Eastin and LaRose(2000)을 비롯해 Joo, Bong. and Choi(2000), Torkzadeh and Dyke(2001), Tsai and Tsai(2003) 등의 연구에서 다양하게 연구되었는데, 이들 연구에서 측정 항목들은 조 금씩 차이가 있지만 모두 Compeau and Higgins (1995)의 컴퓨터 사용에 있어서 자기효능감 측

〈표 2〉표본의 일반적 특징

\begin{tabular}{|c|c|c|c|}
\hline 변수 & 항목 & 표본수(명) & 구성비 $(\%)$ \\
\hline \multirow{2}{*}{ 성별 } & 남 & 113 & 59.2 \\
\hline & 여 & 78 & 40.8 \\
\hline \multirow{5}{*}{$\begin{array}{c}\text { 하루평균 인터넷 } \\
\text { 이용 시간 }\end{array}$} & 30분 미만 & 19 & 9.9 \\
\hline & 30 분 1 시간 미만 & 44 & 23.0 \\
\hline & 1 시간 2시간 & 68 & 35.6 \\
\hline & 2 시간 -3 시간 & 43 & 22.6 \\
\hline & 3 시간 이상 & 17 & 8.9 \\
\hline \multirow{6}{*}{$\begin{array}{c}\text { 인터파크에서 } \\
\text { 제품정보를 } \\
\text { 검색해 보거나 } \\
\text { 구매해 본 제품 } \\
\text { (중복선택) }\end{array}$} & 컴퓨터 관련 제품 & 65 & 34.0 \\
\hline & 책이나 음반 & 89 & 46.5 \\
\hline & MP3 & 23 & 12.0 \\
\hline & 디지털 카매라 & 24 & 12.5 \\
\hline & 의류(캐쥬얼, 정장, 스포츠 등) & 59 & 30.8 \\
\hline & 티켓 (영화, 연극, 뮤지컬. 콘서트 등) & 18 & 9.4 \\
\hline
\end{tabular}


정 방법인 컴퓨터 자기효능감 척도를 기반으로 연구에 맞게 수정한 형태로 이용하고 있다. 특 히, Torkzadeh and Dyke(2001)의 인터넷 자기 효능감 척도는 광범위한 정보처리(information processing)와 자기효능감 관련 문헌을 검토하 여 24 개의 항목을 추출하여 17 개의 항목을 개발 하였다. 이는 브라우징(browsing; 3 개 척도), 암 호화/해독화(encryption/decryption; 6개 척도), 시스템 조작(system manipulation: 8개 척도) 로 구성되어 있다.

본 연구에서는 인터넷 자기효능감을 '인터넷 쇼핑몰을 이용하는 상황에서 자신의 인터넷 사 용능력에 대한 믿음으로 개념적 정의를 하고, 이 개념을 측정하기 위해. Torkzadeh and Van Dyke (2001)의 인터넷 자기효능감 척도를 참고 로 하여, 기존 관련 문헌(이호배, 이현우 2003) 에서 사용된 실용적 브라우징 측정항목을 본 연구 목적에 맞게 수정하여 이용하였다. 브라우 징은 실용적 브라우징과 쾌락적 브라우징으로 나누어 연구되고 있는데, 제품을 찾고 정보를 수집해 가는 효용적인 가치 추구를 목적으로 탐색활동을 하는 것이 실용적 브라우징이며, 탐 색 자체로 재머와 즐거움을 획득하는 탐색활동 은 쾌락적 브라우징으로 정의되고 있다.

본 연구에서는 소비자가 인터넷 쇼핑몰에서 구매를 염두에 두고 제품을 찾고 정보를 탐색 하는 과정으로 볼 수 있기 때문에 쾌락적 브라 우징보다는 실용적 브라우징이 인터넷 자기효 능감을 측정하기에 적합하다고 생각하여 실용 적 브라우징 측정항목을 본 연구 목적에 맞게 수정하여 6개 항목('나는 구입하고 싶은 제품을 좀 더 좋은 조건(가격. 품질 등)으로 구입하기 위해 인터넷 쇼핑몰을 탐색하는 것에 자신이
있다', '나는 인터넷 쇼핑몰을 탐색하여 다양한 제품 정보를 얻는 것에 자신이 있다. '나는 인 터넷 쇼핑몰에서 제품과 관련된 비교정보를 얻 는 것에 자신이 있다', '나는 인터넷 쇼핑몰을 탐색하여 가능한 많은 부가서비스를 얻는 것에 자신이 있다', '나는 인터넷 쇼핑몰을 탐색하여 구매하고자 하는 제품을 효율적으로 구매하는 것에 자신이 있다, '나는 인터넷 쇼핑몰을 탐색 하여 적은 시간을 투자해 많은 제품 정보를 탐 색하는 것에 자신이 있다)을 7점 척도(1: 전혀 그렇지 않다, $7:$ 매우 그렇다)로 측정하였다.

\subsection{2 플로우(flow)}

폴로우(Flow)는 다차원적인 개념이기 때문에 단일차원으로 플로우 구성개념(flow construct) 을 정의하고 측정하는데 어려움이 있어 연구자 들은 플로우의 측정을 위해 가장 밀접한 개념 으로 '자발적 흥미(playfulness)'라는 변수를 도 입하였는데. Bamett(1991)은 자발적 흥미를 가 진 개인(playful individuals)을 “내부적 동기, 자기 자신이 만든 목표를 가지고 과정 지향, 사 물이나 행동에 자기 자신의 의미를 부여하는 경향(즉, 자극에 의해 지배당하는 것이 아닌), 외부적인 규칙으로부터의 자유. 활동적 관여에 의해 이끌어지는 즐겁고, 흥미를 가지는 성향을 가진 사람”으로 정의하고 있다. '자발적 흥미' 는 놀이를 하고 있을 때와 같이 활동자체에 사 용자 스스로가 외부적 보상과 관계없이 새로운 선택과 시도를 하면서 느끼는 경험이며(Webster and Martocchio 1993). Csikszentmihalyi(1990) 는 '자발적 흥미는 플로우의 중요한 척도이고. 개인의 즐거움과 심리적 자극 또는 관심의 인 
지를 포함하는 복합적인 변수라고 하였다.

단일차원의 플로우의 측정('나는 플로우 상태 에 있다)과 숙련도, 도전감. 탐색행동과 같은 변수들과의 관계가 '자발적 흥미'와 이들 변수 들과의 관계와 동일하게 밝혀져(Webster and Martocchio 1992: Webster. Trevino, and Ryan 1993), '자발적 흥미’를 플로우와 가장 밀접한 변수로 생각하며, Novak, Hoffman, and Yung(2000)은 '자발적 흥미'를 이용하여 폴로 우를 조작적으로 개념화하려고 시도하였고 단 일차원의 '자발적 흥미”는 플로우의 핵심변수가 된다고 주장하였다. 또한 '자발적 흥미'도 플로 우와 마찬가지로 개인의 특성(trait)과 경험상 태(state) 모두 반영된 것으로 제시되어 최적자 극 수준이 증가할수록 높은 수준의 '자발적 흥 미’를 경험한다고 예측되었다.

본 연구에서 플로우를 '인터넷 쇼핑몰을 이용 하면서 느끼는 자발적 흥미"로 개념적 정의를 하고, 이 개념을 측정하기 위해서 Webster. Trevino, and Ryan 1993)가 개발한 '자발적 흥 미 측정 항목을 본 연구의 목적에 맞게 수정하 여 6개 항목('나는 인터파크 사이트를 이용할 때 공상의 세계로 들어온 듯한 느낌을 받는다, '나는 인터파크 사이트를 이용할 때 자유로움을 느낀다., '나는 인터파크 사이트를를 이용할 때 창의적인 생각이나 의견이 잘 떠오른다. '나는 인터파크 사이트를를 이용할 때 독자적으로 생 각하고 행동한다는 느낌을 받는다', '나는 인터 퐈크 사이트를를 이용할 때 구매목적과 상관없 이 웹사이트 이용자체가 즐겁다. '나는 인터파 크 사이트를 이용할 때 자발적으로 모든 행동 을 한다는 느낌을 받는다) 을 7점 척도(1: 전혀 그렇지 않다. 7: 매우 그렇다)로 측정하였다.

\subsection{3 지각된 위험}

본 연구에서는 지각된 위험을 '인터넷 쇼핑몰 웹사이트에서 제품을 구매할 때 지각할 수 있 는 위험'으로 개념적 정의하고, Jacoby and Kaplan(1972), 그리고 Jarvenpaa and Todd (1997)에 근거하고, 시간손실 위험, 미래기회 손실 위험(Zikmund and Scott 1977)을 추가하 여, 인터넷 쇼핑 상황에서 가능한 위험을 정리 하여 5 개 항목 ('인터파크 사이트에서 제품을 구매할 때 제품의 가격이 다른 인터넷 쇼핑몰 에서 산 것보다 비쌀까 걱정스럽다', '인터파크 사이트에서 제품을 구매할 때 기대했던 품질이 아닐까봐 걱정스럽다', '인터파크 사이트에서 제 품을 구매할 때 내 개인정보가 유출될 까 걱정 스럽다'. '인터파크 사이트에서 제품을 구매할 때 제품이 마음에 안 들 경우 제품 교환이 어 려울 까봐 걱정스럽다', '인터파크 사이트에서 제품을 구매할 때 앞으로(미래에) 더 싸고 더 성능이 우수한 제품을 다른 곳에서 구매할 수 있을까봐 걱정스럽다)을 7점 척도(1: 전혀 그 렇지 않다. 7: 매우 그렇다)로 측정하였다.

\section{2 .4 태도}

본 연구에서 태도를 '인터넷 쇼핑몰 특정 웹 사이트에 대해서 갖는 호감으로 개념적 정의를 하고, 이 개념을 측정하기 위해 이호배. 정주훈. 박기백(2000)의 연구에서 사용된 웹사이트 태 도 측정항목을 수정하여, 5 개 항목(나는 인터파 크 사이트를 '싫어한다--좋아한다', '마음에 들 지 않는다--마음에 든다', '부정적이다--긍정적 이다, '좋지않다--좋다'. '호감이 가지 않는다- 
호감이 간다)을 7점 척도로 측정하였다.

\section{2 .5 구매의도}

본 연구에서 구매의도는 '인터넷 쇼핑몰에서 제품이나 서비스를 구입할 구매의향'으로 개념 적 정의를 하고, 이 개념을 측정하기 위해서 한 상린, 박천교(2000)에서 이용한 구매의도 척도 를 본 연구에 맞게 수정하여 3개 항목( '인터파 크 사이트를 이용해 다음에도 구매를 할 것이 다'와 '인터파크 사이트를 이용해 구매할 확률 이 있다', '인터파크 사이트를 자주 이용하여 구 매를 할 것이다) 을 7점 척도(1: 전혀 그렇지 않다. 7: 매우 그렇다)로 측정하였다.

\section{$\mathrm{V}$. 분석결과}

\section{1 사전분석}

\section{1 .1 신뢰성 분석}

본 연구에서는 모든 연구개념들을 다항목으로 측정하였으며, 각 연구개념의 내적일관성 검증 을 위해 Cronbach's $\alpha$ 를 계산하였다. 그 결과 인터넷 자기효능감(6항목) $\alpha=.94$. 플로우(6항 목) $\alpha=760$, 웹사이트 태도(5항목) $\alpha=.945$, 웹사이트 구매의도(3항목) $\alpha=.928$ 으로 나타났 으며, 각 연구개념을 위한 척도 중 신뢰성을 저 해하는 항목은 존재하지 않았다. 플로우를 제외 한 다른 연구개념의 신뢰성 계수 값은 국내 이 분야 $\alpha$ 계수 평균인 .7685에 비해 매우 높게 나
타났다(이학식, 김영 1997). 그러나 플로우의 신뢰성 계수 값도 국내 이 분야 $\alpha$ 계수 평균인 .7685보다 약간 낮은 정도로 큰 문제가 없는 것 으로 판단하였다.

\section{1 .2 단일차원성 분석(집중타당성과 대표성)}

신뢰성 분석을 실시한 항목들에 대하여 공분 산 행렬(covariance matrix)를 이용하여 각 연 구개념별 확인 요인분석(confirmatory factor analysis: $\mathrm{CFA}$ )을 실시하였다.

그런데 확인 요인분석을 하기 위해서는 다음 과 같은 두 가지 조건을 갖추어야 실시할 수 있다. 첫째, 연구 개념의 측정항목(indicator)의 수가 두 개 이하인 경우에는 실시할 수 없으며, 세 개인 경우는 모형의 적합도가 계산되지 않 으며(model fit is perfect), 네 개 이상인 경우 에만 요인부하량(factor loading) 과 모형의 적합 도를 계산할 수 있다(이학식, 임지훈 2004). 둘 째, 연구개념의 측정항목은 특성상 반영적 측정 항목(refletive indicator)와 형성적 측정항목 (formative inicator)구분되는데 반영적 측정항 목에 대해서만 확인 요인분석을 할 의미를 갖 는다. 그 이유는 반영적 측정항목들로 구성된 연구개념은 단일차원성을 저해하는 일부 측정 항목을 제거하더라고 그 연구 개념의 의미가 바뀌지 않지만. 형성적 측정항목으로 구성된 연 구개념은 측정항목하나라도 제거하게 되면 그 연구 개념의 의미가 바꿜 수 있기 때문이다 (Jarvis MacKenzie and Podsakoff 2003).

본 연구에 사용된 연구개념 중 지각된 위험은 형성적 측정항목으로 구성되어 있어서 확인요 인분석 과정에서 제외하였다. 따라서 인터넷 자 
기효능감, 플로우, 태도 그리고 구매의도에 대 해서 연구개념별 확인요인분석을 실시하였다. 분 석 과정에서 각 연구 단계별로 최적 상태를 도출 하기 위한 적합도를 평가하기 위해 GFI(Goodnessof-Fit Index: $\geq .90$ 이 바람직), RMSR (Root Mean Square Residual: $\leq .05$ 가 바람직), CFI(Comparative Fit Index: $\geq .90$ 이 바람직), NFI(Normed Fit Index: $\geq .90), \chi^{2}$ (작을수록 바람직 $), \chi^{2}$ 에 대한 $\mathrm{p}$ 값 $(\geq .05$ 가 바람직 $)$ 등을 이용하였다. 그 결과 모형의 적합도가 우수하게 나타났으며, 연구개념별 확인적 요인분석과정(1 차 $\mathrm{CFA}$ )에서 수정지수(modification indices) 4 를 기준으로 측정항목들과 오차항간의 공분산 값이 높게 나타난 인터넷 자기 효능감의 5 번째 항목(b5) 과 플로우의 6 번째 항목(f6) 과 웹사이 트 태도 4번째 항목(a4)을 제거하였다. 1차 확 인요인분석 결과는 〈표 3〉과 같다.

척도들의 잡중타당성 (convergent validity) 과 판별타당성(discriminant validity)을 조사하기 인터넷 자기효능감, 플로우, 태도, 구매의도 항 목들에 대해 동시에 확인요인분석( 2 차 $\mathrm{CFA}$ )을 실시하여 수정지수 4 를 기준으로 단일차원성을 저해하는 항목들을 제거하는 과정에서 항목의 제거로 인한 정보손실을 줄이기 위해 수정지수 6 을 기준으로 각 연구개념에 대해 단일차원성 을 저해하는 항목들을 제거시켰다(Hair, Anderson Tathan, and Black 1995). 2차 확인요인분석 결과 태도 3 번째 항목 (a3)과 구매의도 3번째

〈표 3〉 연구개념별 확인요인분석 결가 $(1$ 차 CFA)*

\begin{tabular}{|c|c|c|c|c|c|}
\hline \multirow{2}{*}{ 연구개념 } & \multicolumn{2}{|c|}{ 측정항목 } & \multirow{2}{*}{ 요인부하량 } & \multirow{2}{*}{$\mathrm{t}$ 값 } & \multirow{2}{*}{ 적합도 } \\
\hline & 최초항목수 & 최종항목 & & & \\
\hline $\begin{array}{c}\text { 인터넷 } \\
\text { 자기효능감 }\end{array}$ & 6 & $\begin{array}{l}b 1 \\
b 2 \\
b 3 \\
b 4 \\
b 6\end{array}$ & $\begin{array}{l}0.964 \\
1.000 \\
0.949 \\
0.903 \\
0.841\end{array}$ & $\begin{array}{c}20.813 \\
- \\
21.305 \\
13.170 \\
13.775\end{array}$ & $\begin{array}{c}\chi^{2}=9.585 \text { d.f. }=5 \\
p=.088 \quad \text { GFI }=.982 \\
\text { AGFI }=.946 \quad \mathrm{NFI}=.988 \\
\text { RMSR }=.036\end{array}$ \\
\hline 플로우 & 6 & $\begin{array}{l}\mathrm{f} 1 \\
\mathrm{f} 2 \\
\mathrm{f} 3 \\
\mathrm{f} 4 \\
\mathrm{f} 5\end{array}$ & $\begin{array}{l}0.959 \\
1.000 \\
0.978 \\
0.687 \\
0.770\end{array}$ & $\begin{array}{c}7.685 \\
- \\
8.013 \\
5.419 \\
5.461\end{array}$ & $\begin{array}{c}\chi^{2}=8.844 \text { d.f. }=5 \\
p=.115 \quad \text { GFI }=.982 \\
\text { AGFI }=.947 \text { NFI }=.960 \\
\text { RMSR }=.067\end{array}$ \\
\hline 태도 & 5 & $\begin{array}{l}\mathrm{a} 1 \\
\mathrm{a} 2 \\
\mathrm{a} 3 \\
\mathrm{a} 5\end{array}$ & $\begin{array}{l}0.868 \\
1.000 \\
0.863 \\
0.937\end{array}$ & $\begin{array}{c}21.395 \\
- \\
17.995 \\
17.345\end{array}$ & $\begin{array}{c}\chi^{2}=5.659 \text { d.f. }=2 \\
p=.059 \quad \text { GFI }=.986 \\
\text { AGFI }=.931 \quad \mathrm{NFI}=.991 \\
\text { RMSR }=.013\end{array}$ \\
\hline 구매의도 & 3 & $\begin{array}{l}\text { pi1 } \\
\text { pi2 } \\
\text { pi3 }\end{array}$ & $\begin{array}{l}0.880 \\
1.000 \\
0.944\end{array}$ & $\begin{array}{c}19.239 \\
- \\
18.359\end{array}$ & - \\
\hline
\end{tabular}

* 3 개의 indicators로 측정된 구매의도의 모형적합도는 계산되지 않음. 
항목(pi3)이 제거되었다. 2차 확인요인분석 결 과는 〈표 4>와 같다.

〈표 4>에 나타난 바와 같이 적합도가 대체로 높게 나타났으며, 각 연구개념들에 대한 요인부 하량이 유의적으로 나타나 $(\mathrm{t}>5.00)$ 로 집중타당성 이 입증되었다(Sujan, Weitz, and Kumar 1994). 추가적으로 척도들이 해당 연구개념들에 대한 대표성을 갖는지 평가하기 위해 연구개념 신뢰 도(construct reliability)와 분산추출값(variance extracted)을 계산하였다(〈표 4〉). 그 결과, 일 반적 기준치(연구개념 신뢰도 .70, 분산추출값 .50)보다 높게 나타나서 해당 연구개념들에 대 한 대표성을 갖는다고 할 수 있다(Hair, Anderson, Tatham, and Black 1995).

\subsection{3 판별타당성 분석}

판별타당성의 검정을 위해 각 연구개념들의 상관관계(〈표 5$\rangle$ 표 참조)를 이용해서 각각의 평 균추출분산(average variance extracted)과 상관 관계제곱값을 비교하였다. Fornell and Larcker (1981)는 어떤 두 연구개념들의 각각에 대한 평균추출분산이 그 두 연구개념들간의 상관관 계제곱값보다 크면 판불타당성이 있다고 하였 다. 본 연구에서 각 연구 개념들의 평균추출분 산값(인터넷 자기효능감 .821, 플로우 .523 , 태 도 884 , 구매의도 .908)이 두 연구 개넘들간 상 관관계제곱값(인터넷 자기효능감과 플로우 .066, 인터넷 자기효능감과 태도 106 , 인터넷 자기효

〈표 4〉 각 연구개념에 대한 확인요인분석 결과 $(2 \text { 차 } \mathrm{CFA})^{\star}$

\begin{tabular}{|c|c|c|c|c|c|c|}
\hline \multirow{2}{*}{ 연구개념 } & \multicolumn{2}{|c|}{ 측정항목 } & \multirow{2}{*}{ 요인부하량 } & \multirow{2}{*}{$\mathrm{t}$ 값 } & \multirow{2}{*}{$\begin{array}{c}\text { 신뢰도 } \\
\text { (Construct } \\
\text { Reliability) } \\
\end{array}$} & \multirow{2}{*}{$\begin{array}{c}\text { 분산추출 } \\
\text { (Average Variance } \\
\text { Extracted) }\end{array}$} \\
\hline & 최초항목수 & 최종항목 & & & & \\
\hline $\begin{array}{c}\text { 인터넷 } \\
\text { 자기호능감 }\end{array}$ & 6 & $\begin{array}{l}\text { b1 } \\
\text { b2 } \\
\text { b3 } \\
\text { b4 } \\
\text { b6 }\end{array}$ & $\begin{array}{l}0.963 \\
1.000 \\
0.949 \\
0.906 \\
0.840\end{array}$ & $\begin{array}{c}20.807 \\
- \\
21.337 \\
13.253 \\
13.770\end{array}$ & .975 & .821 \\
\hline $\begin{array}{l}\text { 플로우 } \\
\text { (flow) }\end{array}$ & 6 & $\begin{array}{l}\text { f1 } \\
\text { f2 } \\
\text { f3 } \\
\text { f4 } \\
\text { f5 }\end{array}$ & $\begin{array}{l}0.918 \\
1.000 \\
0.921 \\
0.694 \\
0.788 \\
\end{array}$ & $\begin{array}{c}7.750 \\
- \\
8.119 \\
5.659 \\
5.771 \\
\end{array}$ & .835 & .523 \\
\hline 태도 & 5 & $\begin{array}{l}\text { a1 } \\
\text { a2 } \\
\text { a5 }\end{array}$ & $\begin{array}{l}0.925 \\
1.000 \\
0.976 \\
\end{array}$ & $\begin{array}{c}21.189 \\
- \\
16.702 \\
\end{array}$ & .952 & .884 \\
\hline 구매의도 & 3 & $\begin{array}{l}\text { pil } \\
\text { pi2 }\end{array}$ & $\begin{array}{l}0.993 \\
1.000\end{array}$ & $\begin{array}{c}17.966 \\
-\end{array}$ & .976 & .908 \\
\hline
\end{tabular}

${ }^{*} \mathrm{~d}, \mathrm{f}=84, \quad \chi^{2}=102.814(\mathrm{p}=.08), \mathrm{RMSR}=101, \mathrm{GFI}=.934, \mathrm{AGFI}=905, \mathrm{NFI}=.948$. 
〈표 5〉 각 연구개념들간의 상관관계

\begin{tabular}{|c|c|c|c|c|c|}
\hline & $\begin{array}{c}\text { 인터넷 } \\
\text { 자기효능감 }\end{array}$ & $\begin{array}{c}\text { 플로우 } \\
\text { (flow) }\end{array}$ & 웹사이트 태도 & $\begin{array}{c}\text { 웹사이트 } \\
\text { 구매의도 }\end{array}$ & 지각된 위험 \\
\hline \hline 인터넷 자기효능감 & & & & & \\
\hline 폴로우(flow) & $0.257^{*}$ & & & & \\
\hline 태도 & $0.326^{*}$ & $0.337^{*}$ & & & \\
\hline 구매의도 & $0.368^{*}$ & $0.258^{*}$ & $0.774^{*}$ & & \\
\hline 지각된 위험 & $-0.240^{*}$ & -0.203 & $-0.369^{*}$ & $-0.307^{*}$ & \\
\hline
\end{tabular}

${ }^{*} \mathrm{p}<01$ 수준에서 유의적임.

능감과 구매의도 .135 , 플로우와 태도 .113 , 태 도와 구매의도 .599)보다 큰 것으로 나타나 판 별타당성이 입증되었다.

\section{2 가설검정결과}

\subsection{1 연구모형의 검정}

전체 연구개념들간의 관계를 조사하기 위해 공분산행렬을 이용하여 본 연구에서 제시한 구 조모형(overall model)을 검정한 결과 최적모형 이 도출되었다 $\left(\chi^{2}=136.207(\mathrm{~d} . \mathrm{f} .=99), \mathrm{p}=.008\right.$, $\mathrm{RMSR}=.152 . \mathrm{GFI}=.920, \quad \mathrm{AGFI}=.889 . \quad \mathrm{NFI}=$ .933) (〈그림 2〉 참조).

\section{2 .2 연구가설 검증결과}

각 연구개념들 간의 관계에 관한 가설을 검정 한 결과는〈표 6)과 같다.

\section{〈그림 2〉 연구가설 검정결과}

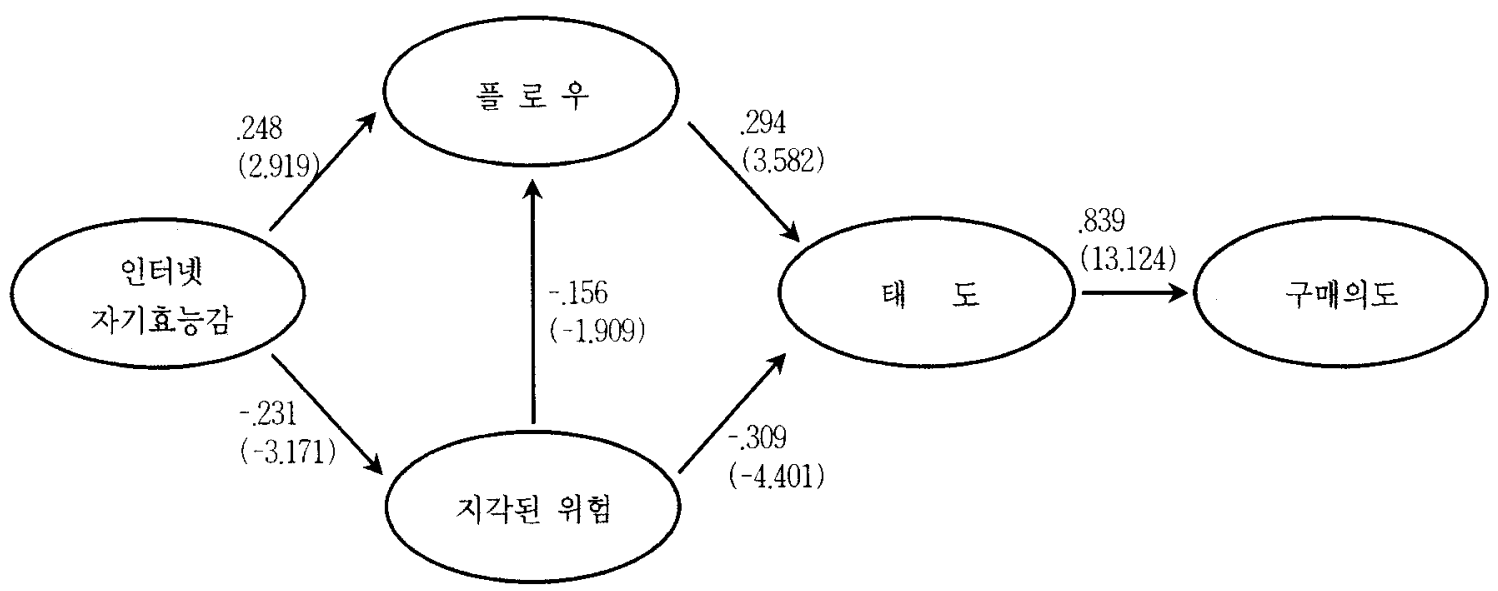

※ 계수값은 표준화된 값이며, ( )의 값은 $\mathrm{t}$ 값임. 
〈표 6〉 각 연구개념들간의 관계에 대한 분석결과

\begin{tabular}{|c|c|c|c|c|c|c|}
\hline 가설 & 경로 & $\begin{array}{l}\text { 가설 } \\
\text { 방향 }\end{array}$ & $\begin{array}{l}\text { 경로 } \\
\text { 명칭 }\end{array}$ & 경로계수 & $\mathrm{t}$ 값 & $\begin{array}{l}\text { 지지 } \\
\text { 여부 }\end{array}$ \\
\hline $\mathrm{H1}$ & 인터넷 자기효능감 $\left(\xi_{1}\right) \rightarrow$ 플로우 $\left(\eta_{1}\right)$ & + & $\gamma_{11}$ & .248 & $2.919^{*}$ & 0 \\
\hline $\mathrm{H} 2$ & 인터넷 자기효능감 $\left(\xi_{1}\right) \rightarrow$ 지각된위험 $\left(\eta_{2}\right)$ & - & $\gamma_{21}$ & -.231 & $-3.171^{*}$ & 0 \\
\hline $\mathrm{H} 3$ & 플로우 $\left(\eta_{1}\right) \rightarrow$ 태도 $\left(\eta_{3}\right)$ & + & $\beta_{31}$ & .294 & $3.554^{*}$ & O \\
\hline $\mathrm{H} 4$ & 지각된위험 $\left(\eta_{2}\right) \rightarrow$ 태도 $\left(t_{k}\right)$ & - & $\beta_{32}$ & -.309 & $-4.351^{*}$ & O \\
\hline $\mathrm{H} 5$ & 태도 $\left(\eta_{3}\right) \rightarrow$ 구매의도 $\left(\eta_{4}\right)$ & + & $\beta_{43}$ & .839 & $11.965^{*}$ & 0 \\
\hline $\mathrm{H} 6$ & 지각된위험 $\left(\eta_{2}\right) \rightarrow$ 플로우 $\left(\eta_{1}\right)$ & - & $\beta_{21}$ & -.156 & -1.909 & X \\
\hline
\end{tabular}

주) 각 경로계수는 포준화된 값임.

* $p<01$ 에서 유의적임(양측검정),

연구가설 검정 결과는 다음과 같은 의미를 갖 는다.

첫째, 가설1(인터넷 자기효능감이 높을수록 플로우를 더 경험하게 될 것이다: $\gamma_{11}=248$, $\mathrm{t}=2.919$ ) 과 가설2 (인터넷 자기효능감이 높을수 록 지각된 위험이 낮아질 것이다: $\gamma_{21}=-231$, $\mathrm{t}=-3.171$ )가 지지됨으로써 인터넷 자기효능감 이 높은 소비자는 특정 웹사이트에서 제품 구 매 시 제품관련 정보탐색을 인터넷 자기효능감 이 낮은 소비자에 비해 더 잘 수행할 것이고 이로 인해 특정 웹사이트 이용에서 더 플로우 를 경험할 것이고 제품 구매를 하려고 하는 상 황에서 지각된 위험을 더 적게 지각할 것이다.

둘째, 가설3(플로우를 더 경험할수록 웹사이 트에 대한 태도가 호의적일 것이다: $\beta_{31}=.294$, $\mathrm{t}=3.554$ ), 가설4(지각된 위험이 낮을수록 웹사 이트에 대한 태도가 호의적일 것이다: $\beta_{32}$ $=-.309, \mathrm{t}=-4.351$ ). 그리고 가설5(웹사이트에 대한 태도가 호의적일 수록 웹사이트에서의 구 매의도가 높아질 것이다: $\left.\beta_{43}=.839, \mathrm{t}=11.965\right)$ 이 지지됨에 따라, 특정 웹사이트를 이용할 때
플로우를 경험하는 소비자는 그 웹사이트에 호 의적인 태도를 갖게 되고, 또한 특정 웹사이트 를 통한 구매를 하고자 할 때 위험을 적게 지 각한다면 그 웹사이트에 호의적인 태도를 가지 게 될 것이다. 이러한 특정 웹사이트에 대한 호 의적인 태도는 특정 웹사이트에서의 높은 구매 의도로 연결될 수 있다.

Hoffman and Novak(1996)은 특정 웹사이트 를 지속적으로 방문하도록 이끄는 것은 플로우 에 달려있으며, 플로우가 온라인 구매의도에 직 접적으로 영향을 주기보다는 웹사이트의 방문 의도가 결과적으로 구매의도를 높여준다고 하 였다. 본 연구의 결과도 이와 같은 맥락에서 플 로우가 특정 웹사이트를 지속적으로 방문하게 하는 원동력이 되며 이는 플로우가 특정 웹사 이트에 대한 호의적인 태도를 유발하기 때문이 라고 생각해 볼 수 있겠다. 기존 플로우 관련 문헌(한상린, 박천교 2000: 두정완 2003)에서 플로우가 구매의도에 직접적으로 미치는 영향 을 밝히지 못하였는데, 본 연구를 통해 플로우 가 구매의도에 직접적 영향을 미치기보다 태도 
를 매개로 구매의도에 영향을 미친다는 것이 확인되었다. 지각된 위헙 또한 인터넷에서의 구 매를 방해한다는 주장(Burke 1997; Guelch and Klein 1997)을 근거로 하여 많은 실증연구 가 이루어졌으나 실증연구에서는 구매의도에 영향을 미치지 않은 것으로 나타난 경우가 있 었다(Jarvenpaa and Todd 1997). 본 연구결과 로 지각된 위험이 구매의도에 대한 직접적인 영향력보다 태도를 매개로 구매의도에 영향을 미친다는 것이 확인되었다.

셋째, 가설6(지각된 위험이 낮을수록 플로우 를 더 경험할 것이다: $\left.\beta_{21}=-.156, t=-1.909\right)$ 은 $\mathrm{p}<0.01$ (양측검정)에서는 비유의적이다. 그러나 $\mathrm{p}<0.5$ 수준에서는 이 가설도 지지되기 때문에 본 연구에서는 지각된 위헙이 낮을수록 플로우 를 더 경험한다는 가설이 한계적으로 지지되었다.

\section{VI. 결 론}

\section{1 연구의 요약 및 논의}

본 연구에서는 소비자가 인터넷 쇼핑몰에서 구매할 때 느끼는 심리적인 부담을 극복하기 위해서 자기 자신의 정보탐색 능력에 대한 신 념이 필요하다고 보고 소비자 자신이 정보탐색 을 잘 수행할 수 있다고 스스로 지각하는 능력 으로서 인터넷 자기효능감이라는 연구개념을 도입하였다. Torkzadeh and Van Dyke(2001) 는 인터넷 자기효능감 척도가 브라우징, 암호화 /해독화, 시스템 조작의 3 가지 요인으로 구성되 어 있다고 하였다. 이중에서 본 연구는 브라우
징 즉, 정보탐색에 관련된 부분으로 한정해서 인터넷 자기효능감으로 보았다.

본 연구는 인터넷 쇼핑 시 소비자의 인터넷 자기효능감 정도가 특정 인터넷 쇼핑몰에서의 구매의도에 미치는 영향을 알아보았다. 이 과정 에서 인터넷 자기효능감이 톡정 인터넷 쇼핑 사이트에 대한 태도에 어떠한 영향을 미치며. 또한 플로우와 지각된 위험에 미치는 영향을 실증분석한 결과는 아래와 같다.

첫째, 인터넷 자가효능감은 플로우에 긍정적 영향을 미치는 반면이 지각된 위험에는 부정적 영향을 미치는 것으로 나타났다. 이것은 인터넷 자기효능감이 높을수록 인터넷을 이용하면서 자발적 흥미를 더 느끼게 되고, 인터넷 쇼핑 구 매에 대한 우려와 걱정을 나타내는 지각된 위 험이 낮아지는 것을 의미한다.

둘째, 플로우는 인터넷 쇼핑 사이트 태도에 긍정적 영향을 미치고, 지각된 위험은 인터넷 쇼핑 사이트 태도에 부정적 영향을 미치는 것 으로 나타났다. 또한 인터넷 쇼핑 사이트에대한 웹사이트 태도는 구매의도에 긍정적 영향을 미 치는 것으로 나타났다. 이것은 소비자가 인터넷 사용을 통해서 자발적 흥미를 느낄수록 인터넷 쇼핑 사이트에 대한 태도가 호의적인 반면 소 비자가 인터넷 쇼핑 사이트에 대해서 느끼는 위험이 클수록 그 사이트에 대한 태도는 비호 의적임을 의미한다. 또한 인터넷 사이트에 대한 태도가 호의적일수록 그 사이트에서 구매할 의 도는 높아진다는 것을 확인할 수 있다.

끝으로, 인터넷 사이트에 대한 지각된 위험이 클수록 폴로우에 부정적 영향을 미친다는 것은 밝혀지지 않았다(유의 수준 $\mathrm{p}<0.01$ ). 그러나 통계적 유의수준 $\mathrm{p}<0.05$ 인 경우에는 유의하 
게 나타났고 방향성도 가설설정방향대로 나타 나서 한계적으로 지지되었다. 즉 통계적으로 지 지되지는 않았지만 지각된 위험이 낮을수록 더 플로우를 즐길 수 있다는 것이 한계적으로 인 정될 수 있다.

한편 본 연구가 갖는 의미는 다음과 같다.

첫째, 본 연구에서는 개인의 인터넷검색능력 에 따라서 인터넷에서의 구매의 성과가 달라질 수 있기 때문 자신의 인터넷 사용능력에 대한 믿음 즉 인터넷자기효능감이 어떤 개념보다 우 선적으로 고려되어야 한다는 점을 밝혀냈다는 데 의의가 있다.

둘째, 기존 플로우 연구들(김명소 1999; 이명 수, 박종희, 김도일 2001; 두정완 2003; Novak et al. 2000)에서는 플로우가 구매의도에 직접 적 영향을 미치는 것에 관한 연구를 하였는데, 본 연구를 통해 폴로우는 구매의도에 직접적 영항뿐만 아니라 태도를 매개로 하여 구매의도 에 영항을 미친다는 것을 발견하였다.

셋째, 컴퓨터에 대한 두려움이라는 개념에서 소비자가 인터넷 쇼핑에 대한 두려움을 가지고 위험을 지각한다면 소비자는 인터넷 쇼핑 상황 (특정 웹사이트)에서 즐거움을 느끼기 어렵고 즐거움을 느낄 수 없으면 웹사이트에 대한 태 도가 부정적일 것이다. 특히 인터넷쇼핑몰이 보 편적인 구매장소가 되기 위해서는 일반사람들 특히 중장년층이 갖고 있는 컴맹 콤플랙스를 없애는 것이 무엇보다 중요하다고 본다. 따라서 인터넷쇼핑몰을 이용하는 것이 생각보다 쉽고 현재의 인터넷사용능력이면 충분하다는 인식을 심어줄 필요가 있다. 실제로 중장년소비자들은 실제로 인터넷을 다룰 수 있는 능력이 있는데 도 불구하고 자신감이 없어서 시도를 못하는
경우가 많다 따라서 본 연구의 결과를 활용해 서 소비자에게 자기효능감을 갖도록 홍보하고 알리게 되면 훨씬 수월하게 인타넷 쇼핑 환경 을 보편화시킬 수 있다.

따라서 인터넷 자기효능감이 높은 소비자는 인터넷 쇼핑에서 성공적으로 제품정보를 탐색 할 수 있다는 자신감을 가지며, 인터넷 쇼핑 상 황에서 즐거움. 흥미를 느끼고, 인터넷 상에서 구매를 하는 것에 대한 위험을 덜 지각할 것이 다. 그러면 소비자가 재미있다고 느끼고, 위험 을 덜 지각할수록 특정 웹사이트에 대해 호의 적인 태도를 형성하고, 결국 이러한 호의적인 태도는 구매의도를 높이게 되고, 이는 구매로 이어질 가능성이 커진다고 할 수 있다. 이러한 점에서 인터넷 쇼핑몰 사이트는 웹 디자인에 있어서 소비자가 정보를 쉽게 찾을 수 있도록 구성해야 하며, 특정 쇼핑몰에서 제품별로 다른 웹사이트와의 비교정보를 제공함으로써 한 쇼 핑몰에서 여러 쇼핑몰의 정보를 한꺼번에 비교 할 수 있도록 구성하는 것이 필요하겠다.

\section{2 연구의 한계 및 향후 연구}

본 연구의 한계점 및 향후 연구방향은 다음 과 같다.

첫째, 본 연구에서는 인터넷 이용률과 인터넷 쇼핑몰 이용 여부를 고려하여 대학생만을 표본 으로 선정하였고, 지역도 서울로 한정하여 다양 한 표본의 특성을 반영하지 못하여 다양한 계 층의 인터넷 쇼핑몰 이용자들의 특성을 반영했 다고 하기에 무리가 있다. 또한 대학생들은 다 름 집단에 비해서 평균 인터넷 이용시간도 많 고 전반적으로 인터넷에 친숙하고 능숙하며 정 
보탐색을 잘하는 집단으로 평가되기 때문에 자 기효능감의 유의성을 검증할 수 있는 충분한 값의 분산을 확보하지 못했을지도 모르고. 보편 적인 소비자의 성향을 나타낸다고 보기 어렵기 때문에 향후 연구에서는 다양한 표본을 대상으 로 자료를 수집하여 일반화 가능성을 높일 수 있는 연구가 필요하다.

둘째, 본 연구에서 인터파크라고 하는 특정 웹사이트에 대한 폴로우, 지각된 위험, 태도, 구 매의도를 측정하였기 때문에 여기에서 나온 결 과를 일반적인 인터넷 쇼핑상황에 적용하기 어 려움이 있다. 더구나 대학생들에게 가장 선호하 는 쇼핑몰 사이트에서 주로 컴퓨터관련 제품처 럼 익히 알고 있는 제품들을 구매하려는 상황 을 기억에 의존해서 응답하도록 했기 때문에 실제보다 더 높은 인터넷 자기효능감이 나타났 을지 모른다. 따라서 향후연구에서는 이러한 사 전 효과를 비롯한 외생변수효과를 배제하기 위 해서 인터넷상에서 가상 웹사이트를 구축하여 웹사이트를 직접 이용해 보게 한 후 플로우와 지각된 위험 등을 측정하는 연구가 이루어져야 하겠다.

세째, 플로우는 복잡한 다차원적 연구개넘임 에도 불구하고 본 연구에서는 플로우 상태와 가장 가까운 변수인 자발적 흥미(playfulness) 로 플로우를 측정하였다. 현재 국내 연구에서는 플로우상태를 측정한 연구가 거의 없다. 향후 연구에서 플로우상태('I am in flow')를 측정하 는 연구가 이루어져야 하며 복잡하고 다차원적 인 변수로 이해하기 어려운 개념인 플로우를 좀 더 구체화하는 연구가 필요하다. 또한 본 연 구에서는 특정 웹사이트를 임의로 정해 피 실 험자의 기억에 의존한 플로우를 측정하였다. 따
라서 측정오차가 발생했을 수 있으며, 기억에 의존하였기 때문에 여러 가지 발생할 수 있는 외생변수를 통제하지 못했다고 할 수 있다.

마지막으로, 인터넷 자기효능감은 인터넷상에 서 소비자 스스로 지각하는 정보탐색(브라우 징)능력에 대한 신념이며 소비자 개인의 특성 이라고 할 수 있다. 따라서 이러한 자기 효능감 을 기업이 통제할 수는 없다는 한계점을 갖지 만, 인터넷쇼핑구매자에게 자신감을 줌으로써 인터넷에 수월하게 접근할 수 있는 사용자 친 화적인 프로그램(예 메뉴방식형 프로그램)의 개발을 통해서 기업통제가 가능할 수 있을 것 이다. 또한 인터넷 자기효능감의 형성에는 어떠 한 선행변수들이 있는지 등의 추가연구가 필요 하다. 또한 인터넷 자기효능감이 웹사이트 태도 에 미치는 영향에서 본 연구에서 제시한 플로 우와 지각된 위험 뿐 아니라 다른 매개변수가 존재할 것이며 이에 대한 연구도 필요하다.

〈논문 접수일: 2006, 02. 28〉

〈게재 확정일: 2006, 06, 19〉

\section{참고문헌}

김명소(1999), "인터넷 사용시의 Flow 경험과 전자상거래를 통한 구매의도와의 관계 모형 개발," 한국심리학회지, 12(5), 한국심리학 회, 197-225.

김상용, 박성용(1999), “전자상거래에서의 구매 의도 결정요인에 관한 연구," 소비자학연 구, 10(3), 한국소비자학회, 45-65. 김종호, 신용섭(2000), "소비자 지각위험 및 구 
매의도 영향요인: 전자상거래 쇼핑몰을 중 심으로," 마케팅과학연구, 6 , 한국마케팅관 리학회, 47-67.

김종호. 신용섭(2004), "인터넷 소핑몰에서의 플 로우와 전형성이 밀착도와 충성도에 미치는 영향," 한국마케 팅저널, 6(1), 한국마케팅 학회, 17-42.

두정완(2003), "Flow 개념과 인터넷상의 소비자 구매의도와의 관계 및 Flow 유형에 따른 구 매행동 차이 분석," 경영학연구. 32(1), 한 국경영학회, 87-118.

문병준, 손용석(2000), “인터넷을 통한 소비자 정보탐색 및 구매행동에 영향을 미치는 요 인: 개념적 연구," 소비자학연구, $11(4)$, 한 국소비자학회, 131-152.

박유식, 한명희(2001), “인터넷 쇼핑몰에서 위험 지각과 품질지각이 구매의도에 미치는 영향,"

마케팅연구, 16(1), 한국마케 팅학회, 59-84. 박철(2000), "인터넷 정보탐색 가치가 인터넷 쇼 핑행동에 미치는 영향에 관한 연구: 쇼핑몰 방문빈도와 구매의도를 중심으로," 마케팅 연구, 15(1), 한국마케팅학회, 143-162. 성영신, 박은아, 이성수(1998), "컴퓨터 사용욕 구와 심리적 경험," 소비자학연구, $9(1)$, 한 국소비자학회. 101-123.

유성진, 최은빈, 김효정(2006), "모바일 인터넷 특성이 플로우 경험에 미치는 영향에 관한 연구," Information Systems Review, 8(1), 한국경영정보학회, 125-139.

이건창, 정남호(2000), "가상현실 기법을 적용한 인터넷 쇼핑몰과 소비자 구매의도에 관한 연구," 경영학연구, 29(3), 한국경영학회, 377-405.
이명수, 박종희, 김도일(2001), "인터넷 상에서 지각된 플로우와 실용적 가치가 구매의도에 미치는 영향에 관한 탐색적 연구." 마케팅 관리연구, 6(1),한국마케 팅관리학회, 61-84. 이시훈(2000), "Flow의 경험집단과 인터넷 광고 의 효과에 관한 연구," 광고학연구, 11(4). 한국광고학회, 135-164.

이학식, 김영(1997), “연구디자인이 Cronbach's $\alpha$ 계수에 미치는 영향," 마케팅연구, 12(1), 한국마케팅학회, 209-222.

임지훈(2004), "브랜드 카리스마, 형성 요인, 그리고 효과: 상징적/기능적 관여도 의 조정적 작용," 마케팅연구, 19(3), 한국 마케팅학회, 137-177.

이호배, 이현우(2003), "인터넷 쇼핑몰에서 브라 우징이 구매충동에 미치는 영향," 경영학연 구, 32(5), 한국경영학회, 1235-1263.

정주훈, 박기백(2000). "인터넷 사이트 에 대한 속성신념과 태도가 홈폐이지 광고 효과에 미치는 영향," 경영학연구, 29(2), 한국경영학회, 263-290.

예종석, 김동욱(2003), "인터넷 이용충족, 플로 우 및 개인적 성향이 인터넷 중독에 미치는 영향," 소비자학연구, 14(2), 한국소비자학 회, $45-83$.

전성률, 허종호, 강석준(2003), "인터넷 쇼핑몰 이용에 따른 소비자의 위험지각과 브랜드와 가격의 상대적 중요성," 소비자학연구, 14 (2), 한국소비자학회, 19-43.

한상린, 박천교(2000), "Flow개념을 이용한 인 터넷 환경에서의 소비자 구매의도 결정오인 분석," 마케 팅연구, 15(1), 한국마케 팅학회, 187-204. 
Aizen, Icek(2002), "Perceived Behavioral Control, Self-efficacy, Locus of Control, and the Theory of Planned Behavior." Journal of Applied Social Psychology, 32(4), 665-683. Akaah, Ishmael P. and Pradeep K. Korgaonkar (1988), "A Conjoint Investigation of the Relative Importance of Risk Relievers in Direct Marketing," Journal of Advertising Research, August/September, 38-44.

Bandura, Albert(1977), "Self-efficacy: Toward a Unifying Theory of Behavioral Change," Psychological Review, 84, 191-215. (1986), Social Foundations of Thought and action: A social cognitive theory, Englewood Cliffs, N. J.: Prentice-Hall. (1997), Self-efficacy: The Exercise of Control, New York: W. H. Freeman.

Barnett, Lynn A.(1991), "The Playfulness:

Definition, Design, and Measurement," Play and Culture, 4(1), 51-74.

Bauer, Raymond A.(1960), Consumer Behavior as Risk Taking, in Hancock, R. S., ed., Dynamic Marketing for a Changing World, Chicago: AMA.

Bettman, James R.(1973). "Perceived Risk and Its Components: A Model and Empirical Test," Journal of Marketing Research, 10. 184-190.

Bozionelos, Nikos(1997), "Psychology of Computer Use: Cognitive Spontaneity as a Correlate of Computer Anxiety and Attitudes Toward Computer Use." Psychological Reports, 80 (2), 395-402.
Burke, Raymond R.(1997), "Do You See What I See? The Future of Virtual Shopping," Journal of the Academy of Marketing Science, 25(4), 352-360.

Compeau, Deborah R. and Christopher A. Higgins(1995), "Computer Self-Efficacy: Development of a Measure and Initial Test," MIS quarterly, 19(2), 189-211.

Cox, Donald F.(1967), Risk Handling in Consumer Behavior: An Intensive Study of Two Cases, in Risk Taking and Informational Handling in Consumer Behavior. Cox, D. F. Ed., Boston: Harvard University Press, 36-37.

Csikszentmihalyi. Mihaly(1977), Beyond Boredoma and Anxiety, San Francisco, CA: JosseyBass. (1990), Flow: The Psychology of Optimal Experience, New York: Harper and Row. and Isabella Csikszentmihalyi (1988). Optimal Experience: Psychological Studies of Flow in Consciousness, Cambridge University Press.

and Judith LeFevre. (1989), "Optimal Experience in Work and Leisure," Journal of Personality and Social Psychology, 56(5), 815-822.

Cunningham, S. M(1967), "The Major Dimensions of Perceived Risk," in Risk Taking and Information Handling in Consumer Behavior, Boston: Harvard University Press, 82-108. Eastin, Matthew A. and Robert LaRose(2000). 
"Internet Self-efficacy and The Psychology of the Digital Divide," Journal of Computer Mediated Communication, 6(1), 1-17.

Fishbein, Martin and Icek Ajzen(1975), Belief, Attitude. Intention, and Behavior, AddisonWesley Publishing Company.

Fornell, Claes and David F. Larcker(1981), "Evaluating Structural Equation Models with Unobservable Variables and Measurement Error," Journal of Marketing Research, 18 (February), 39-50.

Hair, Joseph F. Jr., Rolph E. Anderson, Ronald L. Tatham, and William C. Black(1995), Multivariate Data Analysis with Readings, 4th ed., New York: Macmillam Publishing Company.

Hoffman. Donna L. and Thomas P. Novak (1996), "Marketing In Hypermedia Computer Mediated Environments: A Structural Modeling Approach," Journal of Marketing, 60(July), 50-68.

Hsu, Meng-Hsiang and Chao-Min Chiu(2004), "Internet Self-efficacy and Electronic Service Acceptance," Decision Support System, 38 (2), 369-381.

Jacoby, J. and L. B. Kaplan(1972), "The Component of Perceived Risk," in Venkatesan, M. eds., Proceedings from Third Annual Conference of the Association for Consumer Research, University of Chicago, 382-393. Javenpaa, Sirkka L. and P. A. Todd(1997), "Consumer Reactions to Electronic Shopping on the World Wide Web," Journal of
Electronic Commerce,1(2), 59-88

Jarvis, Cheryl, Scott B. MacKenzie, and Philip M. Podsakoff(2003), "A Critical Review of Construct Indicators and Measurement Model Misspecification in Marketing and Consumer Research," Journal of Consumer Research, 30(2), 199-218.

Joo, Y. J., M. M. Bong, and H. J. Choi(2000), "Self-efficacy for Self-regulated Learning, Academic Self-efficacy, and Internet Seifefficacy in Web-based Instruction," Educational Technology Research and Development, 48(2), 5-17.

Lynch, J. and Dan Ariely(1999), "Electronic Shopping for Wine: How Search Costs for Information on Price. Quality, and Store Comparison Affect Consumer Price Sensitivity, Satisfaction with Merchandise, and Retention," Marketing Science, 19(1), 83-103.

Lutz, Richard J. and Michael Guiry(1994), "Intense Consumption Experience: Peaks, Performances and Flow," Winter Marketing Educators' Conference, St. Petersburg, FL. MacGregor. S. Kim(1999), "Hypermedia Navigation Profiles: Cognitive Characteristics and Information Processing Strategies," Journal of Educational Computing Research, 20(2), 189-206.

Malone. Thomas W.(1981), "Toward a Theory of Instrinsically Motivating Instruction," Congnive Science, 5, 333-370.

Mannell, Roger C., Z. Jiri and R. Larson(1988), 'Leisure States and 'Flow' Experience: 
Testing Perceived Freedom and Intrinsic Motivation Hypotheses," Journal of Leisure Research, 20(4), 289-304.

McCarthy, V.(1997), "Web Security: How Much is Enough?," Dataman, January, 24- 117. Murphy, C.(1988), Assessment of Computer Self-efficacy: Instrument Development and Validation, ERIC Document No. ed.

Nahl, Diane(1996). "Affective Monitoring of Internet Learners: Perceived Self-efficacy and Success," Journal of American Society for Information Sciences, 33, 100-109. (1997). "User-Centered Assessment of Two Web Browsers: Errors, Perceived Self-efficacy, and Success," Journal of American Society for Information Sciences, 34, 89-97.

Novak, Thomas P. and Donna L. Hoffman (1997), "Measuring the Flow Experience Among Web Users, working paper, Vandervilt University. and Donna L. Hoffman and Yiu-Fai Yung (1998). "Measuring the Flow Construct in On-Line Environments: A Structural Modeling Approach", Working paper. Vanderbilt University. (2000), "Measuring

the Customer Experience in Online Environments: A Structural Modeling Approach," Marketing Science, 19(1), 22- 42.

Parasuraman, S. and M. Igbaria(1990), "An Examination of Gender Difference in the Determinants of Computer Anxiety and
Attitudes Toward Microcomputers Among Managers," International Joumal of ManMaching Studies, 32(2), 327-340.

Peter, Paul J. and Michael J. Ryan(1976), “An Investigation of Perceived Risk at the Brand Level," Joumal of Marketing Research. 13(May), 184-188.

Quelch, John A. and Hirotaka Takeuchi(1981). "Nonstore Marketing: Fast Trac Slow?,"

Harvard Business Review, 59(4), 75-84.

Ren, Wen-Hua(1999), "Self-efficacy and the Search for Government Information," Reference \& User Service Quarterly, 38, 283-291.

Roselius, Ted(1971), "Consumer Rankings of Risk Reduction Methods," Journal of Marketing, 35(January), 56-61.

Sheth, Jagdish N. and M. Venkatesan(1968), "Risk-Reduction Process in Repetitive Consumer Behavior," Joumal of Marketing Research, 5(August), 307-310.

Sujan, Harish, Barton A. Weitz, and Nirmalya Kumar(1994), "Learning Orientation, Working Smart, and Effective Selling," Journal of Marketing, 58(July), 39-52.

Tan, Soo Jiuan(1999), "Strategies for Reducing Consumers Risk Aversion in Internet Shopping," Joumal of Consumer Marketing. 16(2), 163-180.

Torkzadeh Gholamreza and Thomas P. Van Dyke(2001), "Development and Validation of an Internet Self-efficacy Scale," Behaviour and Information Technology, 20(4), 275280. 
Trevino, Linda K. and Jane Webster(1992), "Flow in Computer-Mediated Communication," Communication Research, 19(5), 539-573.

Tsai, Meng-Jung and Chin-Chung Tsai(2003). "Information Searching Strategies in WebBased Science Learning: The Role of Internet Self-Efficacy," Innovations in Education and Teaching Intemational, 40(1).

Turkle, S.(1984), The Second Self, Simon and Schuster, New York, NY.

Webster, Jane and Joseph J. Martocchio(1992), "Turning Work into Play: Implications for Microcomputer Software Training," Journal of Management, March, 34-50. Linda K. Trevino and L. Ryan(1993), "The Dimensionality and Correlates of Flow in Human Computer Interactions,"
Computers in Human Behavior, 9, 48-59. Woszczynski, Amy B.. Philip L. Roth, and Albert H. Segars(2002), "Exploring the Theoretical Foundations of Microcomputer Playfulness," Proceedings of the American Conference on Information SystemsAssociation for Information Systems, 4. 45-58.

Zajonc Robert B. and Hazel Markus(1982), "Affective Cognitive Factors in Preferences," Joumal of Consumer Research, 9(September), 123-131.

Zikmund, William G. and Jerome E. Scott (1977), "An Investigation of the Role of Product Characteristics in Risk Perception," Review of Business and Economic Research. 8, 13-34. 


\title{
The Role of Internet Self-efficacy in Internet Shopping
}

\author{
Hobae Lee* \\ Nam Kyeong Kwon**
}

\begin{abstract}
This study suggested the internet self-efficacy construct for explaining consumer's searching information capability. It proposed that consumers who have a high internet self-efficacy feel confident they can search much information which they want to find. And it suggested if consumers have a high internet self-efficacy, they will perceive risk less and will experience flow when they use internet shopping mall also. To examine that effect of internet self-efficacy on flow, perceived risk, attitude, and purchase intention, It suggested hypotheses from the basis of prior studies. All of hypotheses were supported and the findings can be summarized as follows. First, internet self-efficacy had a positive effect on flow and a negative effect on perceived risk. Second, flow had a positive effect on attitude and perceived risk had a negative effect on attitude. Attitude had a positive effect on purchase intention also. In view of the result of analysis, between flow and purchase intention are mediated by and between perceived risk and purchase intention are mediated by attitude also. Finally, perceived risk didn't have an effect on flow.
\end{abstract}

Key words: self-efficacy, internet self-efficacy, perceived risk, flow, purchase intention

* Professor. School of Business Adminstration, Hongik University

** Graduate of Business Adminstration, Hongik University 


\section{INTRODUCTION}

Internet self-efficacy which means the beliefs in one's capabilities to organize and execute courses of internet actions required to produce given attainments, is a potentially important factor to explain the consumers' decisions in e-commerce use, such as internet shopping behavior.

This study examined what is the role of the internet self-efficacy construct for explaining consumer's searching information internet shopping circumstances. It specifically proposed that internet self-efficacy would be the antecedents of flow and perceived risk which influence buying behavior.

There were many researches that addressed the relationships between perceived risk and purchasing attitude and between flow and attitude. But there was few research to find the explanation variables of flow or perceived risk, which is the purpose of this study.

It suggested that if consumers think they have a high internet self-efficacy, they will perceive risk less in buying decision in internet shopping site and also experience flow much more when searching in the internet shopping site.

And internet self-efficacy also would influence the attitude toward internet shopping mall site and purchase intention mediated by flow and perceived risk.

\section{HYPOTHESES}

To examine those effects of internet selfefficacy on flow, perceived risk, attitude, and purchase intention, the research model was suggested such as 〈figure 1〉.

This research model showed 6 hypotheses derived from the reviews on prior studies as follows:

H 1: The greater the internet self-efficacy, the greater is the experience of the flow.

The reasoning for $\mathrm{Hl}$ is that consumer who feels he (she) has good internet self efficacy pursuits the higher challenge for searching for information and then result in intrinsic playfulness after achieving the objective.

H 2: The greater the internet self-efficacy, the lower is the perceived risk.

The reasoning for $\mathrm{H} 2$ is that the good internet self-efficacy consumer is confident of finding the proper information for decision with perceiving risk less.

H 3: The greater the experience of the flow, the more favorable is the attitude toward the internet shopping site. 
〈Figure 1〉 The Research Model

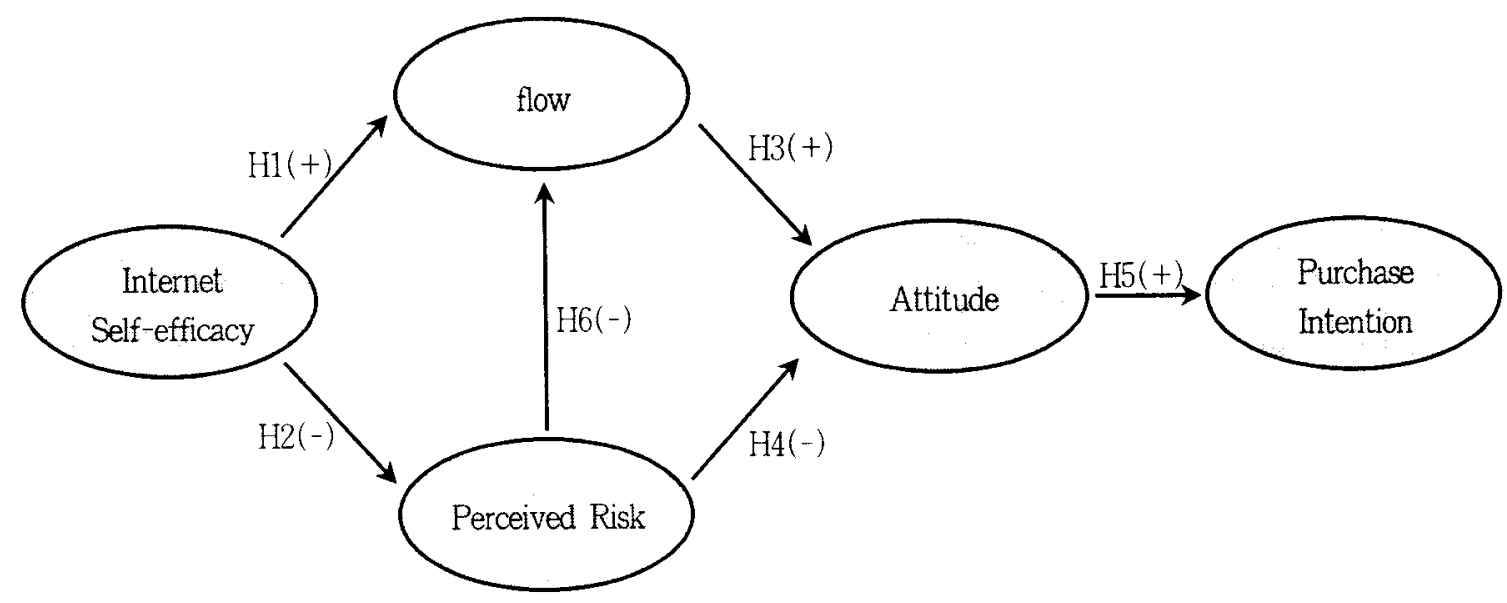

The reasoning for $\mathrm{H} 3$ is that consumer who has liking to the shopping site and visits there frequently forms the favorable attitude toward the site.

H 4: The lower the perceived risk, the more favorable is the attitude toward the internet shopping site.

The reasoning for $\mathrm{H} 4$ is that consumer who experiences the risk less while searching for at shopping site has the positive attitude toward the site.

H 5: The more favorable the attitude toward the internet shopping site, the greater is the purchase intention.

The reasoning for H5 is that consumer with positive attitude toward shopping site has the higher probability to purchase intention as like general off-line purchase situations.

H 6: The lower the perceived risk, the greater is the experience of the flow.

The reasoning for $\mathrm{H} 6$ is that consumer with feels risk less, when finding the right information in shopping site, gains pleasure in surfing the site,

\section{RESEARCH METHOD AND ANALYSIS}

The pilot test with 58 samples was used for selecting the proper internet shopping sites for this study. As a result of pilot test, 'interpark' shopping site(www.interpark.com) was selected for the main test.

The data was collected from the sample of 
〈Table 1〉 The Results of Hypothesis Testing

\begin{tabular}{|c|l|c|c|c|c|}
\hline $\begin{array}{c}\text { Hypothesis } \\
\text { (sign) }\end{array}$ & \multicolumn{1}{|c|}{ Path } & notation & coefficients & t value & $\begin{array}{c}\text { accept or } \\
\text { not }(\mathrm{p}<01)\end{array}$ \\
\hline \hline $\mathrm{H} 1(+)$ & internet self-efficacy $\left(\xi_{2}\right) \rightarrow$ Flow $\left(\eta_{1}\right)$ & $\gamma_{11}$ & .248 & 2.919 & 0 \\
\hline $\mathrm{H} 2(-)$ & internet self-efficacy $\left(\xi_{1}\right) \rightarrow$ perceived risk $\left(\eta_{2}\right)$ & $\gamma_{21}$ & -.231 & -3.171 & 0 \\
\hline $\mathrm{H} 3(+)$ & Flow $\left(\eta_{1}\right) \rightarrow \operatorname{attitude}\left(\eta_{3}\right)$ & $\beta_{31}$ & .294 & 3.554 & 0 \\
\hline $\mathrm{H} 4(-)$ & perceived risk $\left(\eta_{2}\right) \rightarrow$ 태도 $\left(\eta_{3}\right)$ & $\beta_{32}$ & -.309 & -4.351 & 0 \\
\hline $\mathrm{H} 5(+)$ & attitude $\left(\eta_{3}\right) \rightarrow$ purchase intention $\left(\eta_{1}\right)$ & $\beta_{13}$ & .839 & 11.965 & 0 \\
\hline $\mathrm{H} 6(-)$ & perceived risk $\left(\eta_{2}\right) \rightarrow$ Flow $\left(\eta_{1}\right)$ & $\beta_{21}$ & -.156 & -1.909 & $\mathrm{X}$ \\
\hline
\end{tabular}

191 university students who have ever searched for information or purchased in 'interpark' site. The measures of the constructs were cited mainly from previous researches (for instance, internet self-efficacy from Torkzadeh and Van Dyke 2001: flow from Webster, Trevino, and Ryan 1993). All mea- surement scales were represented as 7-points scale.

The reliability of the construct measurement items was tested with Cronbach's $\alpha$ and the unidimensionality of the construct was confirmed with confirmatory factor analysis.

The analysis method of hypotheses was SEM(Structural Equation Model) with AMOS 4.0 statistics package program.

A structural model was estimated to assess path and explained variance estimate. The overall model yielded a good fit $\left(\chi^{2}=136.207\right.$ (d.f. $=99), p=.008, \quad \mathrm{RMSR}=.152, \mathrm{GFI}=.920$, $\mathrm{AGFI}=.889, \mathrm{NFI}=.933$ ).

As results of hypotheses testing, all of hypotheses except H6 were accepted, but
H6("The lower the perceived risk, the greater is the experience of the flow") also was accepted at .5 significance level (see (table 1〉).

\section{RESULTS AND CONCLUSIONS}

From this research, the findings can be summarized as follows;

First, internet self-efficacy had a positive effect on flow and had a negative effect on perceived risk. It means that consumer with good internet self-efficacy could enjoy the flow more during surfing information and feels the perceived risk less when he(she) would decide purchase in internet circumstances.

Second, flow had a positive effect on attitude toward internet shopping mall site. It means that consumer with more experiences of flow in internet shopping has favorable attitude toward the site. It suggested that 
intemet shopping sites needed to provide consumers with playful elements in internet surfing to result in the favorable attitude toward the site.

Third, perceived risk had a negative effect on attitude toward internet shopping mall site. Attitude also had a positive effect on purchase intention. It means that the less the perceived risk, the more favorable is the attitude toward the website. And the more favorable the attitude, the more is the purchase intention on the website.

In addition, there is the mediation effect of flow between internet self-efficacy and attitude and also the mediation effect of perceived risk between internet self-efficacy and attitude.

Finally, though perceived risk didn't have an effect on flow rigorously in statistical perspective, it has impact on flow directionally and marginally( .05 significance level). So consumer who feels the risk less takes more pleasure in surfing on internet somewhat than one who feels the risk more.

There were some limitations of the study as follows:

First, the sample of university students were not representative of general internet shoppers. It needs to be extend to the general consumer in the future research.

Second. the result couldn't be generalized because the data were collected from the only one shopping site("interpark). It needs to be collected data from the various internet shopping sites

Finally, despite of the multidimensions of flow construct, the study examined the only 'playfulness' dimension which is considered as the nearest variable to the flow construct. The future study should consider the other dimensions of flow to examine the interactive effect.

\section{References}

Ajzen, Icek(2002), "Perceived Behavioral Control, Self-efficacy, Locus of Control, and the Theory of Planned Behavior," Journal of Applied Social Psychology, 32(4), 665-683. Bandura, Albert(1977), "Self-efficacy: Toward a Uunifying Theory of Behavioral Change," Psychological Review, 84, 191-215. (1997), Self-efficacy: The EXercise of Control, New York: W. H. Freeman.

Bettman, James R.(1973), "Perceived Risk and Its Components: A Model and Empirical Test," Journal of Marketing Research, 10, 184-190.

Bozionelos, Nikos(1997), "Psychology of Computer Use: Cognitive Spontaneity as a Correlate of Computer Anxiety and Attitudes Toward Computer Use," Psychological Reports, 80(2), 395-402. 
Compeau, Deborah R. and Christopher A. Higgins(1995), "Computer Self-Efficacy: Development of a Measure and Initial Test," MIS quarterly, 19(2), 189-211.

Csikszentmihalyi, Mihaly(1977), Beyond Boredoma and Anxiety, San Francisco, CA: JosseyBass.

(1990), Flow: The Psychology of Optimal Experience, New York: Harper and Row.

and Isabella Csikszentmihalyi

(1988). Optimal Experience: Psychological Studies of Flow in Consciousness, Cambridge University Press.

Cunningham, S. M.(1967), "The Major Dimensions of Perceived Risk," in Risk Taking and Information Handling in Consumer Behavior, Boston: Harvard University Press, 82-108.

Doo, Jeong Wan(2003), "The Relationship between the Flow Construct and Consumers' Buying Intention over the Internet, plus the Difference Test of Buying Behavior by Flow Type," Korean Management Review, 32(1), Korean Academic Society of Business Adminstration, 87-118.

Eastin, Matthew A. and Robert LaRose(2000), "Internet Self-efficacy and The Psychology of the Digital Divide," Journal of Computer Mediated Communication, 6(1), 1-17.

Hoffman, Donna L. and Thomas P. Novak (1996), "Marketing In Hypermedia Computer
Mediated Environments: A Structural Modeling Approach," Journal of Marketing. 60(July), 50-68.

Hsu, Meng-Hsiang and Chao-Min Chiu(2004). "Internet Self-efficacy and Electronic Service Acceptance," Decision Support System. 38. 369-381.

Jacoby, J, and L. B. Kaplan(1972), "The Component of Perceived Risk," in Venkatesan, M. eds., Proceedings from Third Annual Conference of the Association for Consumer Research. University of Chicago, 382-393.

Joo, Y. J., M. M. Bong, and H. J. Choi (2000), "Self-efficacy for Self-regulated Learning, Academic Self-efficacy, and Internet Selfefficacy in Web-based Instruction," Educational Technology Research and Development, 48(2), 5-17.

Kim, JongHo, Yong Seop Shin(2004), "The Effect of Flow and Typicality on Consumer Stickness and Loyalty in the Internet Shopping Mall," Korean Journal of Marketing, 6(1), Korean Marketing Association, $14-42$.

Lee, Hobae and HyunWoo Lee(2003), "The Impacts of Browsing on Buying Impulsiveness in Internet Shopping Malls," Korean Management Review, 32(1), Korean Academic Society of Business Adminstration, 1235-1263.

Lee, Myoung-Soo, Jong-Hee Park, and Doyle $\operatorname{Kim}(2001)$, "A Study on the Effect of 
Internet Shopping Values on Purchase Intention," Journal of Marketing Management Research 6(1). Korean Marketing Management Association, 61-84.

MacGregor, S. Kim(1999). "Hypermedia Navigation Profiles: Cognitive Characteristics and Information Processing Strategies," Journal of Educational Computing Research, 20(2), 189-206.

Mannell, Roger C.. Z. Jiri, and R. Larson(1988), "Leisure States and 'Flow' Experience: Testing Perceived Freedom and Intrinsic Motivation Hypotheses," Journal of Leisure Research, 20(4), 289-304.

Murphy, C.(1988). Assessment of Computer Self-efficacy: Instrument Development and Validation, ERIC Document No. ed.

Nahl, Diane(1996), "Affective Monitoring of Internet Learners: Perceived Self-efficacy and Success." Journal of American Society for Information Sciences, 33. 100-109. (1997), "User-Centered Assessment of Two Web Browsers: Errors, Perceived Self-efficacy, and Success," Journal of American Society for Information Sciences, 34, 89-97.

Novak, Thomas P. and Donna L. Hoffman (1997). "Measuring the Flow Experience Among Web Users, working paper, Vandervilt University.

and Donna L. Hoffman and Yiu-Fai Yung (1998), "Measuring the Flow Construct in On-Line Environments:
A Structural Modeling Approach", Working paper, Vanderbilt University.

Park, Yoo-Sik and Myoung Hi Han(2001), "The Effects of Perceived Risk and Perceived Qualityon the Consumer's Online Buying Behavior," Korean Marketing Review, 16(1), Korean Marketing Association, 59-84.

Ren. Wen-Hua(1999), "Self-efficacy and the Search for Government Information," Reference \& User Service Quarterly, 38, 283-291.

Tan, Soo Jiuan(1999), "Strategies for Reducing Consumers Risk Aversion in Internet Shopping," Journal of Consumer Marketing, 16(2), 163-180.

Torkzadeh Gholamreza and Thomas P. Van Dyke(2001), "Development and Validation of an Internet Self-efficacy Scale." Behaviour and Information Technology, 20(4). 275280.

Trevino. Linda K. and Jane Webster(1992), "Flow in Computer-Mediated Communication," Communication Research. 19(5). 539-573.

Tsai, Meng-Jung and Chin-Chung Tsai(2003), "Information Searching Strategies in WebBased Science Learning: The Role of Internet Self-Efficacy," Innovations in Education and Teaching International, 40(1).

Webster, Jane and Joseph J. Martocchio(1992). "Turning Work into Play: Implications for Microcomputer Software Training," Journal of Management. March, 34-50. Linda K. Trevino, and $\mathrm{L}$. 
Ryan(1993), "The Dimensionality and Correlates of Flow in Human Computer Interactions," Computers in Human Behavior, 9. 48-59.

Ye, Jong-Suk and Dong-Wook Kim(2003), "The Effects of Internet Gratification, Flow, and Personality on the Internet Addiction," Journal of Consumer Studies,
14(2), Korean Society of Consumer Studies, 45-83.

Yoo, SangJin, Eun-Bin, CHoi, and Hyo Jung Kim(2006), "An Empirical Study on the Flow Experience Affected by Characteristics of Mobile Internet," Information Systems Review, 8(1). The Korea Society of Management Information Systems, 125-139. 